\title{
Hypnosis and top-down regulation of consciousness
}

Devin B. Terhune, ${ }^{a}$ Axel Cleeremans, ${ }^{b}$ Amir Raz, ${ }^{c, d}$ \& Steven Jay Lynn ${ }^{e}$

a Department of Psychology, Goldsmiths, University of London, London, UK

b Consciousness, Cognition and Computation Group, Université Libre de Bruxelles, Brussels, Belgium

c Department of Psychiatry, McGill University \& Lady Davis Institute for Medical Research at the SMDB Jewish General Hospital, Montréal, QC, Canada

${ }^{\mathrm{d}}$ Institute for Interdisciplinary Behavioral and Brain Sciences, Chapman University, Irvine, CA, USA

e Department of Psychology, Binghamton University (SUNY), Binghamton, NY, USA

Correspondence address:

Devin B. Terhune

Department of Psychology

Goldsmiths, University of London

London, UK SE14 6NW

d.terhune@gold.ac.uk 


\section{Abstract}

Hypnosis is a unique form of top-down regulation in which verbal suggestions are capable of eliciting pronounced changes in a multitude of psychological phenomena. Hypnotic suggestion has been widely used both as a technique for studying basic science questions regarding human consciousness but also as a method for targeting a range of symptoms within a therapeutic context. Here we provide a synthesis of current knowledge regarding the characteristics and neurocognitive mechanisms of hypnosis. We review evidence from cognitive neuroscience, experimental psychopathology, and clinical psychology regarding the utility of hypnosis as an experimental method for modulating consciousness, as a model for studying healthy and pathological cognition, and as a therapeutic vehicle. We also highlight the relationships between hypnosis and other psychological phenomena, including the broader domain of suggestion and suggestibility and conclude by identifying the most salient challenges confronting the nascent cognitive neuroscience of hypnosis and outlining future directions for research on hypnosis and suggestion.

Keywords: agency; cognitive control; metacognition; placebo; suggestibility; suggestion; therapy 


\section{Contents}

1. Introduction

2. Hypnosis as top-down regulation

3. A hypnosis primer: measurement, individual differences, and phenomenology

4. Hypnotic phenomena

4.1. Motor control

4.2. Perception

4.3. Cognition

5. Instrumental hypnosis

6. Clinical hypnosis

6.1. Suggestion as a therapeutic vehicle

6.2. Evidence base for the therapeutic efficacy of hypnosis

7. Mechanisms and relation to germane phenomena

7.1. Suggestion in a broader context

7.2. Agency and metacognition

7.3. Cognitive control

7.4. Social cognition

7.5. Psychopathology and dissociation

7.6. Neurocognitive bases of hypnosis and hypnotic suggestibility

8. Outstanding questions and future directions 


\section{Introduction}

A remarkable feature of the human brain is its ability translate endogenous mental representations into perceptual states. One of the most striking instances of such top-down regulation is the phenomenon of hypnosis, in which verbal suggestions are capable of eliciting pronounced changes in the contents of consciousness (Oakley \& Halligan, 2013). Following specific suggestions, responsive individuals are able to experience alterations in a diverse array of psychological functions and thus hypnotic suggestion has considerable potential for studying the intersections of cognitive control, sense of agency, metacognition, and germane functions. In turn, hypnosis is becoming increasingly recognized as a valuable method for modeling different psychological phenomena (Cox \& Bryant, 2008; Oakley \& Halligan, 2009), including pathological symptomatology (Woody \& Szechtman, 2011), that may otherwise be resistant to manipulation in controlled settings. Such an approach offers new vistas for cognitive neuroscience. The opportunities afforded by topdown regulation of consciousness in hypnosis extend beyond the laboratory: hypnotic suggestion can be utilized in the treatment of different conditions and disorders (Elkins, 2017) and as an adjunct method for producing analgesia in surgery (Agard et al., 2016; Facco, 2016; Faymonville et al., 1995). Together, these approaches point to hypnosis as a valuable, but understudied, technique for modulating the contents of consciousness with implications for both basic and clinical science.

This review aims to synthesize contemporary research and theory in the domains of clinical and experimental hypnosis research. We first introduce hypnosis as a form of top-down regulation and describe its principal characteristics and provide examples of different psychological phenomena that can be modulated via suggestion. Subsequently, we turn to the use of hypnosis as a method for cognitive neuroscience and experimental psychopathology, describing the rationale of this approach and providing some illustrative examples. Hypnosis has a rich history as a therapeutic vehicle and we next review its use in therapeutic contexts and its clinical efficacy. In describing the mechanisms of hypnosis, we aim to place it in a broader context by considering its relation to different psychological phenomena. We conclude by highlighting outstanding challenges and questions that we anticipate will be the foci of future research. 


\section{Hypnosis as top-down regulation}

Top-down regulation refers to the process whereby mental representations cascade downstream to override physiology, perception, and behaviour. Although persistent reductionism in psychology and neuroscience traditionally led researchers to favor bottom-up explanations in which psychological phenomena are based in low-level neurobiological mechanisms, there is now widespread recognition that mental representations, such as expectations, regularly impact perception (Summerfield \& de Lange, 2014). Moreover, ample evidence has accumulated for a role of long-range signals from, and interactions with, prefrontal and partial cortices in the implementation of top-down control over lower-level brain regions and corresponding psychological functions (Gazzaley \& D’Esposito, 2007; Miller \& Cohen, 2001). Superficially, hypnosis appears as a bizarre or spectacular phenomenon, but it is increasingly being understood as a unique form of top-down regulation that occurs within a culturally-sanctioned social context (Raz, 2011).

Theories of hypnosis frequently highlight the top-down view and tend to emphasize the roles of cognitive control and executive (or metacognitive) monitoring functions based in prefrontal and anterior cingulate cortices and broader frontal-parietal networks (Dienes \& Perner, 2007; Egner \& Raz, 2007; Gruzelier, 2006; Jamieson \& Woody, 2007; Lynn, Kirsch, \& Hallquist, 2008; Woody \& Sadler, 2008). Indeed, despite broad disagreements regarding the specific mechanisms underlying hypnosis, nearly all theories propose that suggestions are implemented through some form of top-down regulation (for an exception, see (Woody \& Bowers, 1994)). On most of these accounts, specific perceptual states and behavioural routines originating from suggestion-based mental representations (rogue representations (Brown \& Oakley, 2004)) are implemented through mundane goal-directed cognitive control mechanisms. However, the hypnotic context, and the expectations, beliefs, motivational states, and cognitive and experiential sets that it engenders, coupled with the wording of suggestions, promotes impaired or atypical monitoring (Brown, Antonova, Langley, \& Oakley, 2001; Dienes \& Perner, 2007; Lynn et al., 2008; Woody \& Szechtman, 2011) and, concomitantly, the perception that one is not the author of one's own behaviour and experience (see §7.2). This distortion in one's sense of agency constitutes the core phenomenological feature of response to suggestion (Bowers, 1981; Polito, Barnier, Woody, \& Connors, 2014; Weitzenhoffer, 
1980). Some theories of hypnosis have emphasized specific top-down factors including response expectancies and there is broad evidence that they contribute to individual differences in hypnotic suggestibility (Lynn et al., 2008). Neuroimaging and brain stimulation research has implicated prefrontal, anterior cingulate, and parietal cortices in different facets of hypnotic responding or in individual differences in hypnotic suggestibility (Cojan et al., 2009; Dienes \& Hutton, 2013; Egner, Jamieson, \& Gruzelier, 2005; Huber, Lui, Duzzi, Pagnoni, \& Porro, 2014; Jiang, White, Greicius, Waelde, \& Spiegel, in press; McGeown, Mazzoni, Venneri, \& Kirsch, 2009; Terhune, Cardeña, \& Lindgren, 2011a), thereby implicating regions known to contribute to the top-down regulation of lower-level brain structures (Gazzaley \& D’Esposito, 2007; Miller \& Cohen, 2001). However, the specific cognitive mechanisms and roles of different cortical and subcortical regions in the implementation of the top-down control that subserves responsiveness to suggestion remains poorly understood (see also §7.6).

\section{A hypnosis primer: measurement, individual differences, and phenomenology}

Hypnosis can be understood as an elaborate form of suggestion that occurs within a specific sociocultural context. In contrast to instructions, which imply self-agency (e.g., "raise your hand"), suggestions are verbal communications for involuntary responses (e.g., "your hand will raise”) (Kirsch, 1999b). Hypnosis involves a set of procedures that are embedded within an interaction between an experimenter (or therapist) and a participant (or client). In contrast to the popular imagination, a typical hypnosis protocol is a relatively mundane affair that is at odds with the many pervasive myths regarding this phenomenon (Raz, 2011). The primary components of hypnosis include an induction followed by one or more suggestions.

Hypnotic inductions can be understood as the first suggestion in a hypnosis protocol (Nash, 2005). Although they vary markedly, most have the intended purpose of promoting an attentional state characterized by absorption in the words of the experimenter and a reduction in endogenous and exogenous awareness (Barber, 1984). The functional role of inductions remains controversial. Inductions are for the most part interchangeable, although certain features of inductions seem to have beneficial properties (Brown et al., 2001) and further research is needed to clarify the extent to which certain elements are wholly unnecessary 
and also how inductions can be optimized (Terhune \& Cardeña, 2016). For example, the use of the word hypnosis can effectively enhance suggestibility (Gandhi \& Oakley, 2005), thereby highlighting the importance of participants' response expectancies and the context. Research has shown that inductions only have a minimal, albeit statistically significant, influence on suggestibility (Braffman \& Kirsch, 1999; Tart \& Hilgard, 1966). By contrast, neuroimaging studies have produced conflicting results regarding the impact of an induction; for instance, one study of suggested colour hallucinations observed similar neurophysiological responses for hypnotic and non-hypnotic suggestions, with relatively minor differences (McGeown et al., 2012), whereas a study using suggestion to modulate pain experience found that hypnotic suggestion produced strong activation changes and more compelling phenomenological changes, thereby implying that suggestion is more effective following an induction (Derbyshire, Whalley, \& Oakley, 2009). The influence of inductions on suggestibility seems to vary depending on the type of suggestion, the mode of assessment, and individual differences in relevant cognitive functions (Terhune \& Cardeña, 2016). Although the sources of this variability are not well understood, there is substantial evidence indicating that the primary causal variable underling responsiveness to suggestion is an individual's level of suggestibility rather than the hypnosis procedure per se.

Following the induction, one or more suggestions will be administered. Suggestions are typically worded as involuntary happenings rather than voluntary actions so as to augment the perception that one is not the author of one's response (Bowers, 1981; Spanos \& Gorassini, 1984). In turn, the primary phenomenological feature of response to suggestion is a distortion in one's sense of agency (Weitzenhoffer, 1974, 1980). Such distortions during hypnotic responding are elevated in high hypnotic suggestibility at a comparable magnitude to disruptions in the sense of agency in passivity symptoms experienced by patients with schizophrenia (Polito, Langdon, \& Barnier, 2015) and are perceived as more similar to truly passive than truly voluntary responses (Haggard, Cartledge, Dafydd, \& Oakley, 2004). A second hallmark feature of response to hypnotic suggestions is the perception that one's response is real (Barnier, Dienes, \& Mitchell, 2008; Kihlstrom, 2008; Woody \& Szechtman, 2007a). This experience of verisimilitude, however, has received less empirical attention and is typically neglected or conflated with involuntariness in different 
psychometric instruments assessing the phenomenology of hypnotic responding (Woody \& Szechtman, 2007b). Barnier and colleagues (2008) have suggested that different types of suggestions (Woody, Barnier, \& McConkey, 2005) may differentially target involuntariness and verisimilitude, such that involuntariness may capture the phenomenology of response to motor (e.g., paralysis) suggestions whereas verisimilitude may characterize the experience of responding to cognitive-perceptual (e.g., hallucination) suggestions. Phenomenological data are partially consistent with this distinction (Comey \& Kirsch, 1999; Polito et al., 2014), but may better reflect an association between the magnitude of experiential response and the (perceived) difficulty of implementing the suggested response (Barnier et al., 2008).

Suggestions can be (partially) divorced from the hypnotic context through the use of posthypnotic suggestions (Barnier \& McConkey, 1999), in which the suggestion is for a particular response after the formal hypnosis session has ceased. These suggestions can be valuable in dissociating the impact of the specific suggestion from any spontaneous effects of the induction, such as changes in attention and perception (Cardeña, 2005; Egner \& Raz, 2007; Pekala \& Kumar, 2007). Posthypnotic suggestions have been used extensively in instrumental research, in which suggestions are administered in order to produce experimental analogues of different psychological and neurological phenomena (see §5), as well as in neuroimaging research on a range of hypnotic phenomena (Mendelsohn, Chalamish, Solomonovich, \& Dudai, 2008) and may be valuable in certain therapeutic contexts (Lynn, Rhue, \& Kirsch, 2010). Despite their utility, there is psychometric evidence that posthypnotic suggestions may be qualitatively distinct from hypnotic suggestions (Sadler \& Woody, 2004; Woody, Barnier, et al., 2005) and thus it remains unclear to what extent the two types of suggestions have distinct and overlapping mechanisms.

Responsiveness to hypnotic suggestions (hypnotic suggestibility or hypnotizability) can be reliably measured using standardized scales (Woody \& Barnier, 2008). The measurement of hypnotic suggestibility typically involves a relaxation-based induction followed by suggestions of varying difficulty and content that usually target motor control, perception, and cognition (Bowers, 1993; Shor \& Orne, 1962; Weitzenhoffer \& Hilgard, 1962). Suggestions are scored on the basis of overt behavioural responses, although these can be complemented with additional self-report scales indexing experiential response to the suggestions (Kirsch, 
Council, \& Wickless, 1990; Kirsch, Milling, \& Burgess, 1998; Polito, Barnier, \& Woody, 2013), which can help to discriminate compliant from genuine response to suggestion (Bowers, Laurence, \& Hart, 1988). Factor analytic work suggests that hypnotic suggestibility scales are best modeled by a core factor of hypnotic suggestibility and ancillary specialized factors that are non-redundant and contribute unique variance to individual differences in response to specific suggestions above and beyond the core latent variable (Woody, Barnier, et al., 2005).

It has long been established that individuals display marked variability in their responsiveness to hypnotic suggestions (Laurence, Beaulieu-Prévost, \& du Chéné, 2008). Inter-individual differences on standard scales typically conform to a normal distribution (Laurence et al., 2008; Woody \& Barnier, 2008) (but see (Oakman \& Woody, 1996)), with approximately 10-15\% of the population displaying low hypnotic suggestibility, characterized by non-responsiveness or response to only a few suggestions, $60-80 \%$ displaying moderate responsiveness, and 10-15\% exhibiting high hypnotic suggestibility, characterized by responsiveness to the majority of the suggestions including difficult cognitive-perceptual suggestions. Hypnotic suggestibility exhibits moderate to high stability over 15 to 25 year periods (Morgan, Johnson, \& Hilgard, 1974; Piccione, Hilgard, \& Zimbardo, 1989), which suggests that it can be considered a trait-like characteristic. Research using the twin study methodology further suggests that hypnotic suggestibility is hereditable (Morgan, 1973; Morgan, Hilgard, \& Davert, 1970), although only preliminary research has been conducted on its genetic basis, with conflicting results (Rominger et al., 2014). There is evidence that suggestibility can be modified through pharmacological (Whalley \& Brooks, 2009) and psychological (Gorassini, 2004) interventions, although the magnitude and reliability of these effects is poorly understood.

Individual differences in hypnotic suggestibility form the backbone of all experimental hypnosis research. The reliable identification of individuals of different groups is paramount for experimentally studying hypnotic suggestion in the laboratory and the omission of formal hypnotic suggestibility screening from research studies can often render results ambiguous. Most studies concern highly suggestible individuals, the population for whom the majority of suggestions are effective (Barnier, Cox, \& McConkey, 2014; Heap, Brown, \& Oakley, 2004). Research designs frequently include low suggestible participants as 
controls, although medium suggestible individuals may be a more effective control group for certain studies because they are more representative of the general population (Lynn, Kirsch, Knox, Fassler, \& Lilienfeld, 2007).

\section{Hypnotic phenomena}

The set of phenomena widely associated with hypnotic inductions and suggestions, often referred to as the domain of hypnosis (Kihlstrom, 2008), covers a diverse array of psychological phenomena, highlighting the scope of suggestion and the opportunities for impact in different areas of psychology, psychiatry, and neuroscience. Within this domain, it is important to distinguish between spontaneous cognitive and perceptual changes that are attributable to the induction and those that are suggested (Cardeña, 2005). Following an induction, participants will experience changes in a variety of dimensions of consciousness including affect, awareness, body image, and time perception (Pekala \& Kumar, 2007). A number of these features are driven by suggestions embedded within the induction including for relaxation, heaviness of the body, and attentional absorption (Shor \& Orne, 1962), but some of these experiential effects are still present with a minimal induction that strips away explicit suggestions (Cardeña, 2005; Cardeña, Jonsson, Terhune, \& Marcusson-Clavertz, 2013). Although poorly understood, these effects are plausibly driven by a confluence of variables including response expectancies, implicit or explicit sociocultural beliefs about the hypnotic context, and the influence of repetitive verbal communication. In this subsection we review some of the principal suggested phenomena that have been studied within experimental hypnosis research.

\subsection{Motor control}

Owing in part to the close historical association between hypnosis and the class of phenomena referred to as conversion symptoms, the induction and modulation of motor control has played a central role in the study of hypnosis since its inception (Gauld, 1992; Hull, 1933). Early research, for instance, studied the influence of suggestion on body swaying (Hull, 1933) and the majority of the items on hypnotic suggestibility scales developed in the $20^{\text {th }}$ century include a motor component (Woody \& Barnier, 2008). Motor suggestions can 
be demarcated on the basis of whether they concern the execution of a specific motor response (facilitative) or the suppression of a motor response (inhibitory), with the latter being associated with greater difficulty and, concomitantly, lower rates of responsiveness (Woody, Barnier, et al., 2005).

Facilitative motor suggestions have primarily been used to study distortions in the sense of agency, with potential implications for delusions of control (Blakemore, Oakley, \& Frith, 2003). Preliminary research suggests that responses to ideomotor suggestions more closely resemble truly passive responses than truly voluntary responses (Haggard et al., 2004). In this study, participants viewed a rotating clock hand and judged when they made one of three finger responses: a voluntary response, a suggested involuntary, and a passive response. It was found that participants made anticipatory temporal estimates for voluntary responses whereas their estimates for suggested involuntary responses were significantly different and closer to those for truly passive responses. Cumulatively, these results suggest that suggested involuntary responses are perceived as more similar to passive than to voluntary responses (see also (Moore \& Obhi, 2012)). These effects bear a striking resemble to other non-hypnotic delusions of control present in the general population, such as facilitated communication, where an individual will misattribute their control to another person (Burgess et al., 1998; Wegner, 2002), or possession states, where an individual perceives their experiences and behaviours to be directed by an external non-material source, such as a deity (Bhavsar, Ventriglio, \& Bhugra, 2016; Cardeña, Van Duijl, Weiner, \& Terhune, 2009). One fMRI study compared suggested alien control over a motor response with a voluntary motor response in highly suggestible individuals (Walsh, Oakley, Halligan, Mehta, \& Deeley, 2015). They observed reduced activation in left supplementary motor area (SMA) and increased connectivity between SMA and precuneus and other regions, in the alien control, relative to the voluntary response, condition during a preparation phase when the instructions/suggestions were being given. There is consistent evidence that pre-SMA and SMA play critical roles in the sense of agency (Kühn, Brass, \& Haggard, 2013; Moore, Ruge, Wenke, Rothwell, \& Haggard, 2010) and so these results appear to corroborate highly suggestible individuals' perceptions of reduced authorship over motor responses after specific suggestions. 
Inhibitory motor suggestions have typically involved motor paralysis and may be useful in the study of psychogenic paralysis (Vuilleumier, 2014). An fMRI study found that suggested paralysis was characterized by a qualitatively distinct neurophysiological pattern relative to voluntary inhibition and simulated paralysis in highly suggestible individuals (Cojan et al., 2009). Specifically, whereas voluntary inhibition and simulated paralysis were associated with increased inferior frontal gyrus activation, suggesting the recruitment of prefrontal inhibitory control mechanisms, such effects were not observed in suggested paralysis. Rather, suggested paralysis was associated with increased activation of precuneus and increased connectivity between motor cortex and precuneus, thereby suggesting an important role for precuneus in implementing this distinct form of inhibition. However, motor preparation during suggested paralysis was relatively similar to other forms of inhibition, suggesting the retention of movement intentions. This is important as it implies that suggested paralysis is distinct from functional paralysis, where there appears to be a loss of such intentions (Cojan et al., 2009). Moreover, functional paralysis is associated with increased activation of ventromedial prefrontal cortex, which was not observed in this study, thereby further suggesting important differences between these phenomena (Vuilleumier, 2014).

Other research has highlighted important inter-individual differences in the mechanisms supporting suggested paralysis (Galea, Woody, Szechtman, \& Pierrynowski, 2010; Winkel, Younger, Tomcik, Borckardt, \& Nash, 2006) (see also §7.5). In one study of medium suggestible individuals, the authors observed two distinct motor strategies during the implementation of arm paralysis: one subset of participants displayed trembling and increased bicep activation, as recorded by electromyography, during arm paralysis whereas a second subset did not tremble and displayed lower bicep activation, even though the two groups displayed comparable behavioural and experiential responsiveness to the suggestion (Winkel et al., 2006). Similar variability was observed in a second study among highly suggestible individuals (Galea et al., 2010) and is consistent with a broader literature pointing to the use of differential response strategies, and potentially the recruitment of different mechanisms, across participants (McConkey \& Barnier, 2004). Elucidating the neurocognitive basis of differential response strategies represents an important challenge for future research on hypnotic suggestion. 


\subsection{Perception}

Although less studied than motor control, a range of different facets of perception have been investigated using hypnotic suggestion and provide further evidence regarding the extent to which suggestion can modulate consciousness. Hypnosis can be used to reliably produce hallucinations in some highly suggestible individuals (Woody \& Szechtman, 2011), thereby providing opportunities to study a phenomenon that is normally intractable within laboratory contexts (see also §5.2). In particular, researchers have used suggestion to induce auditory and visual hallucinations (Kosslyn, Thompson, Costantini-Ferrando, Alpert, \& Spiegel, 2000; McGeown et al., 2012; Szechtman, Woody, Bowers, \& Nahmias, 1998), as well as more complicated multimodal hallucinations (Nash, Lynn, \& Stanley, 1984; Röder, Michal, Overbeck, van de Ven, \& Linden, 2007). For example, one study found that suggestions for autoscopy (a visual hallucination of one's own body) coupled with a suggestion for disembodiment (the perception of being physically detached from one's body) was associated with reduced activation in right temporal parietal junction and medial prefrontal cortex relative to a control condition (Röder et al., 2007). This is notable because previous research has shown that direct electrical stimulation of right temporal parietal junction in an epilepsy patient reliably produced out-of-body experiences (Blanke, Ortigue, Landis, \& Seeck, 2002); the latter result provides indirect corroboration of the neurophysiological effects of specific suggestions. Other studies have shown that suggestions for altered colour perception can reliably produce changes in colour-processing regions (fusiform gyri, including V4), and that these effects are distinct from imagining the corresponding colour changes (Kosslyn et al., 2000; McGeown et al., 2012). Outside of the domain of hallucinations, further research has used suggestion to examine the impact of perceptual alterations on automaticity by inducing robust novel crossmodal associations and by modulating congenital synaesthesia (Cohen Kadosh, Henik, Catena, Walsh, \& Fuentes, 2009; Terhune, Cardena, \& Lindgren, 2010).

Due to its clinical implications, the most widely studied perceptual effect in hypnosis is pain modulation (Patterson \& Jensen, 2003). Since the nineteenth century, hypnotic suggestion has been consistently used to treat pain and can be efficacious in certain contexts. Striking examples of this include the reliable efficacy of 
hypnotic suggestion to attenuate pain in the surgical suite (Agard et al., 2016; Facco, 2016; Faymonville et al., 1995). Empirical research has begun to demonstrate the efficacy of suggestion for pain modulation and its specificity. One fMRI study found that suggested pain was associated with activation of a broad network including insula, thalamus, and prefrontal, anterior cingulate, and parietal cortices that closely corresponded to activation patterns associated with pain whereas imagined pain was associated with a qualitatively distinct pattern of activation (Derbyshire, Whalley, Stenger, \& Oakley, 2004). This complements the foregoing research on hallucinations and again demonstrates that suggestion is implemented through distinct neurophysiological mechanisms from imagination. Pain research has further highlighted the specific effects of suggestion on brain states. For example, early neuroimaging research on hypnotic suggestion demonstrated how suggestion could be used to effectively dissociate the sensory and affective components of the pain experience (Rainville, Carrier, Hofbauer, Bushnell, \& Duncan, 1999; Rainville, Duncan, Price, Carrier, \& Bushnell, 1997). Relatedly, another study highlighted the specificity of suggested pain modulation: hypnotic suggestibility predicts responsiveness to suggested analgesia but not another analgesia treatment (Patterson, Hoffman, Palacios, \& Jensen, 2006). These results highlight the utility of hypnotic suggestion in modulating specific components of conscious states.

\subsection{Cognition}

Hypnosis is sometimes colloquially referred to as a form of "attentive receptive concentration" and many researchers have viewed hypnosis through the lens of attention (Crawford, Brown, \& Moon, 1993; Egner \& Raz, 2007). Attention refers to both the preparedness for and selection of certain aspects of our physical environment (e.g., objects) or some ideas in our memory. It is comprised of separate control modules which

draw on discrete and largely orthogonal neural circuitry (Raz \& Buhle, 2006). Attention represents one of the core - and most widely studied - facets of human cognition. Considering how suggestion can be used to modulate attention thus may provide a valuable starting point for determining how hypnosis fits into the broader cognitive milieu (Raz, 2012).

The use of hypnotic suggestion to modulate selective attention has been repeatedly demonstrated 
(Iani, Ricci, Gherri, \& Rubichi, 2006; Raz, Fan, \& Posner, 2005; Raz, Kirsch, Pollard, \& Nitkin-Kaner, 2006). These and other studies have shown that suggestions for altered visual perception can be used to enhance performance in selective attention tasks such as Stroop and Flanker tasks. For instance, by impairing highly suggestible individuals' ability to read colour words (alexia), Stroop congruency effects can be substantially attenuated or, in some cases, eliminated. As noted above, this approach has been extended to the disruption of crossmodal automaticity effects (Dery, Campbell, Lifshitz, \& Raz, 2014; Terhune et al., 2010). Preliminary neuroimaging research has demonstrated that these suggestions produce a reduction in neurophysiological markers of conflict monitoring, thereby indicating that the effect is not occurring through the enhancement of cognitive control but by obviating the need for cognitive control (Raz et al., 2005; Terhune et al., 2010). The former study presented further evidence that the suggestion was influencing low level visual processing (Raz et al., 2005), although the cognitive and perceptual stages at which suggestion implements effects on consciousness have received only little attention. Moreover, although hypnotic suggestions have been reliably shown to modulate attention and improve task performance, it remains unclear whether they can actually de-automatize cognitive functions (Augustinova \& Ferrand, 2012). Insofar as these studies have enhanced performance on a classic selective attention by altering visual perception using suggestion, it will be important to contrast them with other psychological interventions for enhancing attention that may directly target attentional subsystems, such as meditation (Raz \& Lifshitz, 2016).

Perhaps the most widely studied cognitive phenomenon in the domain of hypnosis is memory (Kihlstrom, 1997; Laurence \& Perry, 1988). It is well established that suggestion in and out of the context of hypnosis can be used to reliably induce false memories (Loftus, 1997) and hypnosis was among the first methods used to induce false memories in the laboratory (Laurence \& Perry, 1983). As with most other hypnotic phenomena, the induction of robust false memories through hypnotic suggestion is most robust with suggestible individuals, but researchers have also reliably induced false memories with medium and low suggestible individuals (Lynn, Matthews, \& Barnes, 2009). The hypnotic context is unnecessary to produce false memories (Barnier \& McConkey, 1992) although there is evidence that it actually seems to increase confidence in memories independently of accuracy and thereby may contribute to the compelling nature of 
false memories (Lynn et al., 2009). The other most widely studied suggestion-based memory phenomenon is amnesia. Hypnotic amnesia suggestions have been shown to target explicit memory, leaving implicit memory intact (Kihlstrom, 1997). A major benefit of using suggestion to model both phenomena is that suggestions can be cancelled leading to a disruption of the false memory or amnesia episode. Similarly, not all highly suggestible individuals are responsive to false memory and amnesia suggestions (McConkey \& Barnier, 2004), thereby permitting the inclusion of non-responsive highly suggestible individuals as controls (Allen, Iacono, Laravuso, \& Dunn, 1995). Cumulatively, these beneficial design features demonstrate how suggestion-based memory distortions can be valuable analogues of disorders of autobiographical memory and functional amnesia (Bryant, Barnier, Mallard, \& Tibbits, 1999; Kihlstrom, 1997; Mendelsohn et al., 2008). Little attention has been directed toward the neural basis of suggested memory aberrations but one fMRI study pointed to a role for anterior prefrontal cortex in the inhibition of memory retrieval in posthypnotic amnesia and that this may occur at a pre-retrieval monitoring stage (Mendelsohn et al., 2008), thereby highlighting the potential utility of hypnosis in decomposing the processes that are altered in functional amnesias. The use of suggestion to modulate memory also nicely ties in with the use of suggestion to modulate beliefs in order to study delusions in controlled settings (Connors, 2015) (see §5.2).

Hypnosis has been used to study a wide variety of other cognitive phenomena but these research programmes have not been systematic and thus only hint at further possibilities of this method. For instance, only preliminary research has used suggestion to induce agnosia (Weitzenhoffer \& Hilgard, 1967), visuospatial processing (Priftis et al., 2011), or changes in affect (Wheatley \& Haidt, 2005) or decision making (Ludwig et al., 2013). More broadly, although it is unlikely that suggestion will effectively modulate low-level biological functions, relatively little is known about the psychological limits of hypnotic suggestion, namely which psychological functions are impervious to the influence of suggestion. Similarly, as described above, performance enhancement through hypnotic suggestion is typically produced by disrupting some type of cognitive or perceptual barrier to optimal performance. Accordingly, an outstanding question is whether suggestion can be used to enhance performance through the direct modulation of cognitive functions. 


\section{Instrumental hypnosis research}

As illustrated in the foregoing sections, hypnotic suggestion can be reliably used to modulate the contents of consciousness in highly suggestible individuals in ways that can provide insights into top-down regulation. Research that aims to elucidate the mechanisms and characteristics of hypnosis and suggestion is typically referred to as intrinsic research (Reyher, 1962). By contrast, hypnosis is also often used to induce and modulate specific cognitive and perceptual states in order to test predictions regarding the features of these phenomena (instrumental research). Instrumental research represents a valuable approach because suggestion can sometimes permit the flexible control of otherwise liminal or intractable phenomena in a controlled context (e.g., delusions; (Connors, Barnier, Coltheart, Cox, \& Langdon, 2012)), thereby allowing for the possibility of modeling different phenomena, or testing otherwise challenging predictions (Cox \& Bryant, 2008). Instrumental research can be further conceptually divided into modeling studies, which aim to establish and validate a hypnotic analogue of a phenomenon and hypothesis-driven studies, whose objective is to use a hypnotic analogue to test predictions regarding a specific phenomenon. Although limited by its necessary reliance on highly suggestible individuals and the practical challenges of identifying and recruiting such individuals, instrumental research can offer a degree of control that may not be otherwise permissible with certain phenomena (e.g., hallucinations) and thereby serves as a method that can nicely complement the use of more traditional research techniques.

Owing to the difficulty of studying pathological symptoms in controlled contexts, instrumental research has been perhaps most widely applied as a technique for experimental psychopathology (Woody \& Szechtman, 2011). An example of this line of work comes from a study by Woody and colleagues, who used hypnotic suggestion to test predictions from a security-motivation theory of obsessive-compulsive disorder (Woody, Lewis, et al., 2005). The authors were motivated by the hypothesis that obsessive-compulsive behaviour derives from a disruption of the feeling of knowing that an action has been sufficiently executed (Szechtman \& Woody, 2004). Low and highly suggestible participants imagined touching a filthy substance and were randomly allocated to conditions where they were told that the substance was or was not potentially 
toxic and that their feeling of knowing that they were clean was or was not blocked by suggestion. The authors found that highly suggestible individuals selectively spent more time washing their hands when the substance was considered potentially harmful and their feeling of knowing had been blocked and experienced less satisfaction from handwashing when their feeling of knowing had been blocked (Woody, Lewis, et al., 2005). In another line of research, hypnotic suggestion has been used to produce compelling analogues of a variety of clinical delusions including mirrored-self misidentification (Connors et al., 2012) and folie à deux (Freeman, Cox, \& Barnier, 2013) (for a review, see (Connors, 2015)). Some of these studies have further used this approach to test predictions derived from specific models of delusions (Langdon \& Coltheart, 2000). Research has also used hypnotic suggestion to study the phenomenological, behavioural, and/or neurophysiological characteristics of visuospatial neglect (Priftis et al., 2011), motor paralysis (Cojan et al., 2009; Deeley et al., 2013), amnesia (Mendelsohn et al., 2008; Terhune \& Brugger, 2011), hallucinations (Szechtman et al., 1998), and alien control states (Blakemore et al., 2003; Deeley et al., 2014; Walsh et al., 2015).

Neuroimaging research of suggested pathological phenomena have identified important neurophysiological correspondences between hypnotic analogues and the respective phenomenon being modeled, but also potentially important differences (Oakley \& Halligan, 2013; Vuilleumier, 2014) (see also §7.6). For example, both conversion and hypnotic paralysis seem to involve strong activations of precuneus, whereas only the former is associated with activation of ventromedial prefrontal cortex (Cojan et al., 2009). Moreover, although hypnotic analogues may represent a valuable technique for modeling pathological conditions, researchers should be mindful of differences in the neurocognitive mechanisms underlying the expression of particular symptoms within a disorder and those that are associated with the implementation of the suggestion. Accordingly, an enduring challenge in instrumental research will be to dissociate behavioural and neurophysiological correlates of the induced phenomenon from those associated with the induction of the phenomenon through suggestion. This may be especially challenging when modeling functional disorders and symptoms that are characterized by frontal inhibition of lower brain regions (Vuilleumier, 2014). 


\section{Clinical hypnosis}

The principal goal of clinical hypnosis is to use suggestion to channel and harness perceptual states and behaviours geared toward therapeutic objectives. For example, hypnotic suggestions can be effective in modifying perception or promoting distraction to attenuate pain (Montgomery, DuHamel, \& Redd, 2000; Patterson, 2010). As empirical research on hypnosis has grown, so too has clinical hypnosis become a viable tool in the armamentarium of many practitioners. An array of theoretical approaches that incorporate hypnotic methods include: (a) psychoanalytic and ego state therapy (Brown \& Fromm, 1986); (b) cognitive behavioral therapy (Kirsch, Capafons, Cardeña-Buelna, \& Amigo, 1999); (c) approaches based on the clinical hypnosis practitioner Milton H. Erickson, who pioneered different forms of indirect suggestions and brief strategic interventions (Erickson, Rossi, \& Rossi, 1976); and, most recently, (d) mindfulness and acceptance-based interventions (Lynn, Malaktaris, Maxwell, Mellinger, \& van der Kloet, 2012). In this section, we describe the use of hypnotic suggestion as a therapeutic technique and review its clinical efficacy.

\subsection{Suggestion as a therapeutic vehicle}

Therapists can exert considerable flexibility in crafting suggestions, which often invite and challenge patients to engage in new and adaptive patterns of thinking, feeling, and behaving. Suggestions often focus on (a) positive coping with anticipated future events, such as in behavioral rehearsal or role playing an assertive interpersonal encounter; (b) cultivating a relaxation response in everyday life and resilience in the face of stressors or aversive events; (c) exploring, evaluating, or reframing historical events; (d) evaluating experiences from an observer perspective; and (e) enhancing confidence, happiness and well-being, energized living, self-efficacy, mastery, compassion directed toward the self and others, a positive motivational/expectational set, and compliance with therapeutic interventions (Elkins, 2017).

Most suggestions used in a therapeutic context, including those for relaxation, calmness, and imagining are easy to experience and do not require high levels of hypnotic suggestibility. Accordingly, they are potentially helpful to many patients (Barber, 1985). Therapeutic suggestions are often individually tailored 
and can be delivered in a formal, indirect, or more conversational style, replete with anecdotes, metaphors, and analogies. Typically, few or no differences in responsiveness are evident as a function of suggestion wording, so long as the response intent of the suggestion is clear (Lynn, Neufeld, \& Mare, 1993).

Suggestions appear to be equally effective regardless of the manner of administration (Bentler \& Hilgard, 1963; Van Der Does, Van Dyck, Spinhoven, \& Kloosman, 1989), but the extent to which this can be extrapolated to clinical practice has yet to be determined.

Hypnosis in a sense can be understood as self-hypnosis because patients are ultimately responsible for generating, and becoming engrossed in, suggested experiences irrespective of whether the suggestions are self-administered or given by a therapist. When explicitly defined as self-hypnosis, hypnotic procedures are cost-effective, portable, can be used in a variety of contexts, and are generally as effective as suggestsions administered by a therapist (Hammond, Haskins-Bartsch, Grant, \& McGhee, 1988). The use of self-hypnosis can also be valuable to promote carryover of treatment effects in extra-therapeutic milieus (Laidlaw \& Willett, 2002).

\subsection{Evidence base for the therapeutic efficacy of hypnosis}

Systematic reviews and meta-analyses of hypnotic interventions have yielded promising evidence for the use of hypnosis in treating a range of specific conditions whereas data are more equivocal for other conditions. Hypnosis is typically used as an adjunctive intervention that supplements or is weaved into another treatment and it is most advantageous when implemented to enhance the effectiveness of an already established empirically supported approach. For example, a meta-analysis of 18 studies found that the average client receiving cognitive-behavioral hypnotherapy displayed greater improvement than at least $70 \%$ of clients receiving the same non-hypnotic cognitive-behavioral treatment (Kirsch, Montgomery, \& Sapirstein, 1995). Individuals who undergo hypnotic interventions exhibit superior outcomes than control patients - typically no treatment, usual treatment, or wait-list controls - in studies of treatment effectiveness of irritable bowel syndrome ( 8 randomized controlled trials [RCTs]) (Schaefert, Klose, Moser, \& Häuser, 2014), chronic pain (6 RCTs, 6 clinical trials) (Adachi, Fujino, 
Nakae, Mashimo, \& Sasaki, 2014), psychosomatic disorders (21 RCTs) (Flammer \& Alladin, 2007), depression (6 RCTs) (Shih, Yang, \& Koo, 2009), and patients with a codable ICD-10 disorder (e.g., anxiety) or those undergoing medical interventions (57 RCTs) (Flammer \& Bongartz, 2003). There is also evidence for superior outcomes for hypnosis than control treatment in outcomes related to surgical patients (20 studies) (Montgomery, David, Winkel, Silverstein, \& Bovbjerg, 2002) and surgical or medical patients (34 RCTs) (Tefikow et al., 2013), reduced nausea and vomiting in patients undergoing chemotherapy (6 RCTs) (Richardson et al., 2007), and reduced needle-related pain and distress in children and adolescents (7 trials) (Birnie et al., 2014). By contrast, further research is needed to more adequately evaluate the use of hypnosis in the treatment of post-traumatic stress disorder (Lynn \& Cardeña, 2007), anxiety (Schoenberger, Kirsch, Gearan, Montgomery, \& Pastyrnak, 1997), smoking cessation (Green \& Lynn, 2000), and obesity (Sapp, 2017).

Despite this evidence pointing to the potential clinical efficacy of hypnosis, very little attention has been devoted to the mechanisms by which it achieves therapeutic effects. Hypnosis often includes many components (relaxation, imagery, symptom-specific suggestions) and thus isolating the efficacy of specific components represents a formidable challenge. Similarly, few studies have assessed the effectiveness of hypnosis in designs that include placebo controls for nonspecific effects, alternative treatments, and wait-list controls in the context of RCTs with an adequate sample size. In addition, although hypnotic suggestibility is a robust predictor of response to suggestion in laboratory contexts (Laurence et al., 2008; Woody \& Barnier, 2008), its predictive utility is much weaker, albeit still statistically significant, in clinical contexts

(Montgomery et al., 2000). Hypnosis appears to be a promising and highly cost-effective clinical intervention that awaits additional rigorously controlled studies to confirm its place among empirically well-established treatments.

\section{Mechanisms and relations with germane phenomena}

Historically, the correlates of hypnotic suggestibility have proved to be elusive (Laurence et al., 2008). For example, aside from preliminary evidence indicating that highly suggestible individuals exhibit greater 
verbal and motor automaticity (Braffman \& Kirsch, 2001; Dixon, Brunet, \& Laurence, 1990; Dixon \& Laurence, 1992) and poorer executive functioning (Farvolden \& Woody, 2004; Khodaverdi-Khani \& Laurence, 2016), they do not have a reliably distinct cognitive profile. Similarly, at present, there are relatively few consistent personality correlates of hypnotic suggestibility (Cardeña \& Terhune, 2014). Nevertheless, there are a number of encouraging research paths pointing to associations between hypnosis and hypnotic suggestibility and a range of germane phenomena which collectively may shed light on individual differences in hypnotic suggestibility and the mechanisms of suggestion.

\subsection{Hypnotic suggestion in a broader context}

Although hypnosis is commonly regarded as a unique phenomenon, it actually can be understood as a member of a broader class of phenomena that are driven by suggestion and individual differences in suggestibility (Gheorghiu, Netter, Eysenck, \& Rosenthal, 1989; Halligan \& Oakley, 2014). Suggestion, in its general form, may refer to any environmental cue that produces an involuntary change in an individuals' beliefs, experiences, behaviour, and corresponding physiological states (Kirsch, 1999a). Suggestions are administered vocally by an experimenter or clinician within the context of hypnosis, but can be non-vocal, such as a list of side effects associated with a drug (Wager \& Atlas, 2015), or non-verbal, such as advertisements or social cues (Halligan \& Oakley, 2014). Perhaps one of the most striking phenomena that is driven in part by suggestion is the placebo effect, whereby an inactive substance or ineffective treatment produces effects congruent with participants' expectancies, such as symptom relief or pain reduction (Benedetti, 2013; Wager \& Atlas, 2015). Hypnosis has been referred to as a non-deceptive placebo (Kirsch, 1999a) and there is preliminary evidence that placebo responsiveness is related to hypnotic and non-hypnotic suggestibility, although the results are not as yet fully conclusive (De Pascalis, Chiaradia, \& Carotenuto, 2002; Lund et al., 2015; Nitzan et al., 2015; Sheiner, Lifshitz, \& Raz, 2016; Woody, Drugovic, \& Oakman, 1997). Similarly, it remains unclear to what extent hypnotic suggestibility is related to different forms of non-hypnotic suggestibility: researchers have observed mixed results pertaining to this association and thus it 
seems to depend on a number of constraints including the mode of assessment (Braffman \& Kirsch, 1999; Gudjonsson, 2013; Kotov, Bellman, \& Watson, 2004; Tasso \& Perez, 2008).

Despite these inconsistencies, it has been shown that placebo responsiveness, proneness to suggestionbased memory distortions, and hypnotic suggestibility are all associated with empathy (Colloca \& Benedetti, 2009; Swider \& Babel, 2013; Tomes \& Katz, 1997; Wickramasekera \& Szlyk, 2003), thereby implying that suggestibility may be related to the broader tendency to be influenced by social contextual cues. In a more extreme form, social cues can function as suggestions that elicit illness, as is the case with mass psychogenic illness (Jones et al., 2000; Mink, 2013). In this phenomenon, illness symptoms such as nausea seem to spread within a cohesive social group, in particular through the observation of other individuals presenting with symptoms (Jones et al., 2000). To our knowledge, no research has measured suggestibility in symptomatic individuals but there is preliminary, albeit mixed, evidence that suggestibility is elevated in patients presenting functional symptoms (Brown \& Reuber, 2016; Roelofs et al., 2002). Cumulatively, these results suggest parallels between hypnosis and suggestion and suggestion-based phenomena more broadly but these associations remain poorly understood.

Typically, suggestions are verbal statements, akin to instructions, but devoid of the coercive character of the latter. There is now a substantial body of research documenting how mere instructions can modulate cognitive processes generally taken to be automatic, such as certain forms of conditioning (Cook \& Harris, 1937; Mertens, Raes, \& De Houwer, 2016; Raes, De Houwer, De Schryver, Brass, \& Kalisch, 2014). For instance, one study used a fear-conditioning paradigm in which participants initially exposed to neutral stimuli paired with fear-eliciting stimuli (i.e., an electric shock) later showed a fear response to the neutral stimuli, hence demonstrating associative affective learning (Mertens et al., 2016). The authors observed that neutral stimuli merely associated with information about the possibility of their being associated with an electric shock later elicited the same changes in skin conductance as when they had actually been associated with the occurrence of an electric shock. This demonstrates that abstract information (i.e., instructions) can to a large extent substitute for actual experience in learning situations, and support the notion that high-level, abstract processes can penetrate deeply into the base of the cognitive hierarchy to influence low-level, 
automatic responses such as skin conductance. These results beg the question of how suggestion relates to instructions. Early research highlighted behavioural and phenomenological differences between suggestion and instruction (Barber, 1969) but, the extent to which these and other forms of communication share overlapping and distinct neurophysiological mechanisms is unclear.

\subsection{Agency and metacognition}

Sense of agency refers to the perception that we are the author of our own actions (Haggard et al., 2004; Moore \& Obhi, 2012). It is a fundamental aspect of individuality and forms the basis for judgements of responsibility (Moore, 2016). The sense of agency is embodied: it is rooted in our ability to distinguish between events that we caused and events that were caused by external factors, and this ability in turn depends upon learned interoceptive signals that inform us about the contingency between our own actions, their consequences in the world, and our internal states. The mechanism of efference copy, whereby the motor system interacts with perceptual systems each time an action is carried out, enables predictive mechanisms to compute expectancies about the perceptual consequences of actions that we carry out something that is impossible for events that we do not cause ourselves and/or those that are not the product of statistical regularities in our environment (Moore \& Haggard, 2010). This prediction-driven perspective on agency also readily accounts for well-known phenomena such as sensory attenuation, that is, the observation that the sensations associated to actions that we carry out tend be attenuated compared to the sensations caused by an external factor (Blakemore, Frith, \& Wolpert, 1999; Blakemore, Wolpert, \& Frith, 1998).

Empirically, the sense of agency has often been studied through probes regarding the extent to which they feel they exert control over their actions (Bowers, 1981; Polito et al., 2013). Insofar as such reports can be contaminated by social desirability (for instance, to deny responsibility) and other biases, many studies have also used implicit measures of agency, which are typically based on the phenomenon of intentional binding (Moore \& Obhi, 2012): action-outcome intervals are perceived to be shorter for intentional actions than for unintended actions, such as when a movement is passive. As described above, previous research 
using a similar paradigm suggests that suggested involuntary motor responses are perceptually more similar to truly passive responses than truly voluntary movements (Haggard et al., 2004).

Numerous theories of hypnosis have attributed distorted agency during hypnotic responding to a disruption of executive monitoring or metacognition (Dienes \& Perner, 2007; Hilgard, 1977; Kirsch \& Lynn, 1998; Miller, Galanter, \& Pribram, 1960). For example, cold control theory (Dienes \& Hutton, 2013; Dienes \& Perner, 2007) maintains that the conscious experience of intention is mediated by the occurrence of higher-order thoughts, secondary (metacognitive) states about one's mental representations (Rosenthal, 2005), that explicitly and accurately index authorship and other features of target first-order actions or representations. This theory proposes that hypnotic responding is supported by normal executive control mechanisms yet characterized by an attenuation in the sense of agency because an individual does not experience higher-order thoughts pertaining to her or his intentions. Thus, according to this view, a response to a suggestion is characterized by a first-order intention to implement the suggested response but the intention fails to become conscious in virtue of the fact that the individual does not form an accurate higherorder thought pertaining to the source of the action.

Cold control theory has recently received empirical support through a study investigating the relationship between hypnotic suggestibility and awareness of intentions (Lush, Naish, \& Dienes, 2016), as measured by the Libet paradigm (Libet, Gleason, Wright, \& Pearl, 1983). In the Libet paradigm, participants are asked to perform a simple action (lifting one's index finger) at a time of their choosing. They are simultaneously required to monitor a clock's face and to estimate the time at which they first felt the urge to act. By subtracting the time at which the action actually occurs from the estimated time of an individual's immediate intention to act, one can obtain a measure of the extent to which an individual's subjective experience of intending to act corresponds to the time of their action. As a test of cold control theory, Lush et al. (2016) hypothesized that highly suggestible individuals' awareness of their intention to act would be temporally delayed because of impaired metacognition pertaining to motor intentions. This prediction was supported; the authors further found that meditators displayed earlier awareness of motor intentions than nonmeditators, which is consistent with research suggesting that meditation and mindfulness are associated with 
superior metacognition (Jo, Hinterberger, Wittmann, \& Schmidt, 2015) and thus are qualitatively distinct from hypnosis (Dienes, Lush, Semmens-Wheeler, \& Naish, 2016). These results suggest that highly suggestible individuals exhibit impaired metacognition pertaining to motor intentions and are consistent with the view that hypnosis involves the strategic relinquishing of metacognition, rather than a disruption in executive control itself. Although the neural basis of this effect has not yet been studied, these results are consistent with research showing that highly suggestible individuals exhibit diminished resting state activation of medial prefrontal cortex (McGeown et al., 2009), a critical node of the default mode network (DMN; Buckner, Andrews - Hanna, \& Schacter, 2008; Raichle, 2015) - a core network associated with spontaneous cognition, self-related cognition, and mind-wandering (Christoff, Gordon, Smallwood, Smith, \& Schooler, 2009; Mason et al., 2007), including metacognitive judgments pertaining to the sense of agency (Miele, Wager, Mitchell, \& Metcalfe, 2011). Cumulatively, these results suggest a critical role for metacognition in hypnotic responding although further research is required to determine the specificity of atypical metacognition in highly suggestible individuals and the specific features of the hypnotic context and individual suggestions that interact with atypical metacognition to produce distortions in the sense of agency during hypnotic responding.

\subsection{Cognitive control}

It is readily apparent that hypnosis involves some form of top-down regulation but the specific cognitive control mechanisms underlying response to suggestion are poorly understood. As described above, many models of hypnosis place greater emphasis upon changes in monitoring functions, rather than control per se (Dienes et al., 2016; Hilgard, 1974; Woody \& Sadler, 2008) (but see Woody \& Bowers, 1994). Some research has observed activation of a frontal-parietal network during response to suggestion (McGeown et al., 2012), implying a role for cognitive control in the implementation of the response. However, there is no consistent, robust evidence that highly suggestible individuals have superior cognitive control; rather, some data suggest that they may actually exhibit impaired control (or broader executive functioning) at baseline or following an induction (Egner \& Raz, 2007), although these results have not always been reliable (see also 
$\S 7.5)$. Indirect, but complementary, evidence for a role of cognitive control in hypnosis comes from developmental research on hypnotic suggestibility, which peaks in preadolescence (around 8-12 years of age), declines in adolescence, and plateaus in adulthood (London, 1965; Morgan \& Hilgard, 1978-79; Rhue, 2004); this trend fits well with maturation of prefrontal cortex (Demacheva, Aubert-Bonn, Lucero, Ladouceur, \& Raz, 2012), although there are competing explanations for this developmental trajectory (Rhue, 2004). Nevertheless, prefrontal cortex supports a diverse array of psychological functions and thus further hypothesis-driven developmental research on hypnotic suggestibility is required to clarify whether and how such trends relate to broader cognitive development.

Independently of the implementation of suggested responses, multiple neuroimaging studies have presented evidence pointing to atypical coupling between brain regions supporting monitoring and control processes during selective attention tasks or at rest in highly suggestible individuals (Cojan, Piguet, \& Vuilleumier, 2015; Egner et al., 2005; Jiang et al., in press). The interpretation of these results is somewhat limited as they have alternately been observed at baseline or following an induction, the direction of the coupling has varied across studies, and none have observed phenomenological or behavioural correlates. Nevertheless, these results are broadly congruent with models proposing that responses to suggestion are implemented through cognitive control in conjunction with a disruption or reduction of monitoring (Dienes \& Perner, 2007; Egner et al., 2005; Jamieson \& Woody, 2007). Future research will be better served by further investigating the relations between monitoring and control functions rather than exploring the possibility that highly suggestible individuals are characterized by superior cognitive control.

\subsection{Social cognition}

A variety of theoretical frameworks and formal models of hypnosis have addressed the social cognitive aspects of hypnotic responsiveness (Lynn et al., 2008). By emphasizing hypnosis as a social behaviour, this orientation has guided research on the interaction between the participant/patient and the experimenter/therapist. In support of this approach, hypnotic suggestibility has been shown to relate to the emotional bond with the hypnotist, the perceived power of the hypnotist, and fear of negative appraisal 
(Nash, 1997). Other research has examined rapport and attunement with the hypnotist including the intensity, synchrony/reciprocity, and resonance of the interpersonal relationship (e.g., postural similarity, mirroring, subjective and imaginal experiences) (Varga \& Varga, 2009) and the impact of the hypnotist's characteristic style on the experiences of the participant (Varga \& Kekecs, 2015). Social factors, such as rapport, are hypothesized to motivate participants to please the hypnotist, enhance positive response expectancies, encourage behavioral compliance, and minimize task-irrelevant or distracting thoughts (Lynn, Laurence, \& Kirsch, 2015). Rapport may promote a "preparedness to respond" set or motivated cognitive commitment to respond in which suggestion-related experiences have an effortless or involuntary quality (Sheehan, 1991; Tellegen, 1981). This experiential set may be primed by suggested experiences, positive attitudes, beliefs, motivation, and expectancies regarding hypnosis (Lynn, Snodgrass, Rhue, Nash, \& Frauman, 1987). Indeed, motivation and response expectancies are robust and stable predictors of hypnotic responsiveness, although the magnitude of these effects is not yet fully clear (Benham, Woody, Wilson, \& Nash, 2006; Braffman \& Kirsch, 1999).

Rapport in hypnosis is significantly correlated with suggestion-related involuntariness and experienced to a greater extent by highly suggestible individuals (Lynn et al., 1987). An intervention that increased participant rapport with the experimenter engendered enhanced hypnotic responsiveness (Gfeller, Lynn, \& Pribble, 1987). However, highly suggestible participants persist in being responsive to suggestions, even in the face of interpersonal exchanges prior to hypnosis that effect low rapport (Lynn et al., 1991), implying that low rapport does not vitiate a robust cognitive commitment to respond in these individuals. In a related line of research, highly suggestible individuals countered their preconceptions about hypnosis in favor of responses consistent with the intent of the hypnotist whereas low suggestible role-playing participants behaved in terms of their preconceptions about hypnosis (Dolby \& Sheehan, 1977; Sheehan, 1991). An independent line of research found that rapport interacted with expectancies in determining hypnotic responsiveness, including the experience of non-volition (Lynn, Nash, Rhue, Frauman, \& Sweeney, 1984).

Further research has begun to identify how hypnotic suggestibility may relate to a cognitive profile 
characterized by heightened responsiveness to social cues (Wickramasekera, 2015). Wickramaekera has highlighted the parallels between rapport and empathy and shown that hypnotic suggestibility positively relates to empathy (Wickramasekera \& Szlyk, 2003). Complementary research has observed positive associations between hypnotic suggestibility and emotional contagion (Cardeña, Terhune, Loof, \& Buratti, 2009) and negative associations between hypnotic suggestibility and alexithymia (Frankel, Apfel-Savitz, Nemiah, \& Sifneos, 1977). However, interpretation of these findings must be guarded in that the causal direction of the link between these variables and hypnotic suggestibility has yet to be ascertained. Further research is needed to integrate these strands of research with contemporary social cognitive neuroscience research on empathy, self-other confusion, and related constructs (de Guzman, Bird, Banissy, \& Catmur, 2016).

\subsection{Psychopathology and dissociation}

The distortions in conscious states produced by hypnotic suggestion bear striking resemble to aberrations in agency, awareness, and metacognition in psychiatric conditions including conversion disorder and schizophrenia (Bell, Oakley, Halligan, \& Deeley, 2011; Polito et al., 2015). Although such correspondences led the $19^{\text {th }}$ century neurologist Charcot to speculate that hypnosis was a pathological phenomenon (Gauld, 1992), it has been consistently shown that the majority of highly suggestible individuals do not suffer from elevated levels of psychiatric symptomatology and thus high hypnotic suggestibility should not be interpreted as inherently pathological (Lynn, Meyer, \& Shindler, 2004).

Nevertheless, since the late nineteenth century, hypnosis has been theoretically tied to the phenomenon of dissociation, a constellation of cognitive and perceptual alterations characterized by a disruption of normally integrated psychological systems (Bell et al., 2011). The association between hypnotic responding and dissociation has typically been viewed through the lens of executive monitoring and metacognition: the dissociation or disruption of these processes is widely hypothesized to underlie response to suggestion in highly suggestible individuals (Dienes \& Perner, 2007; Hilgard, 1974; Woody \& Sadler, 2008). It has repeatedly been shown that clinical populations characterized by pronounced dissociative tendencies, 
including dissociative identity disorder, conversion disorder, and posttraumatic stress disorder, display elevated suggestibility (Bell et al., 2011; Brown \& Reuber, 2016; Terhune \& Cardeña, 2015), although the evidence in patients presenting functional symptoms is somewhat mixed (Brown \& Reuber, 2016). By contrast, hypnotic suggestibility does not reliably correlate with dissociative tendencies in the general population (Dienes et al., 2009) and thus any influence of the latter on the former may be dependent on other as of yet unidentified cognitive and neurophysiological factors. On the basis of these apparent discrepancies and other data pointing to pronounced heterogeneity in the upper range of hypnotic suggestibility (Hilgard, 1979; King \& Council, 1998; McConkey \& Barnier, 2004), a number of researchers have proposed a dissociative subtype among highly suggestible individuals (Barber, 1999; Brown \& Oakley, 2004; Carlson \& Putnam, 1989). Preliminary evidence for this subtype has been observed: they seem to comprise approximately one-third of highly suggestible individuals and display impaired baseline working memory and poorer cognitive control following an induction and seem to respond to suggestions with fewer cognitive resources, and greater distortions in agency (King \& Council, 1998; Terhune, Cardeña, \& Lindgren, 2011b, 2011c). These preliminary results suggest that inter-individual differences in dissociative tendencies may account for heterogeneity among highly suggestible individuals although further research is required to corroborate the dissociative subtype and further elucidate its principal characteristics and its implications for the role of dissociation in psychopathology more generally (Bell et al., 2011; Terhune \& Cardeña, 2015).

\subsection{Neurocognitive bases of hypnosis and hypnotic suggestibility}

With the advent of cognitive neuroscience, the application of functional neuroimaging to the study of hypnotic phenomena has helped to validate the phenomenological reports of highly suggestible individuals and has begun to shed light on the neurophysiological basis of suggestion and the neurocognitive profile of highly suggestible individuals (Landry \& Raz, 2017; Oakley \& Halligan, 2013). Many researchers have traditionally viewed the question of whether hypnosis is an altered state of consciousness as one of the most critical questions confronting our understanding of this phenomenon (Kallio \& Revonsuo, 2003; Mazzoni, Venneri, McGeown, \& Kirsch, 2013) and numerous neurophysiological studies have been guided by this 
question, or interpreted results with reference to altered states of consciousness (Jamieson \& Burgess, 2014; Mazzoni et al., 2013). By contrast, we maintain that the pursuit of the markers of a putative hypnotic state has distracted researchers away from more substantive mechanistic research questions and has created unproductive theoretical divisions. In our view, the resolution of this question, namely whether hypnosis is or is not an altered state of consciousness, is unlikely to lead to any significant theoretical advances and thus we think that greater progress will be made by pursuing hypothesis-driven research targeting specific cognitive functions and neurophysiological mechanisms (Woody \& McConkey, 2003). In our view, the two central challenges in the nascent cognitive neuroscience of hypnosis include elucidating the neurophysiological signatures of hypnotic suggestibility and the neurophysiological mechanisms of suggestion.

Owing to its role in monitoring and cognitive control (Fleming, Ryu, Golfinos, \& Blackmon, 2014; Miller \& Cohen, 2001), multiple theories of hypnosis have hypothesized a role for atypical prefrontal functioning in high hypnotic suggestibility (Dienes \& Hutton, 2013; Gruzelier, 2006; Woody \& Bowers, 1994). Multiple well-powered behavioural studies have suggested that highly suggestible individuals exhibit impaired performance on cognitive tasks known to depend on prefrontal cortex, such as selective attention and working memory (Farvolden \& Woody, 2004; Jamieson \& Sheehan, 2004; Khodaverdi-Khani \& Laurence, 2016; Terhune et al., 2011c). Some of these effects have been observed at baseline whereas others have been restricted to a hypnotic induction, thereby clouding interpretation. These studies suggest in a preliminary fashion that high hypnotic suggestibility may be associated with impaired frontal functioning, but the specificity of this impairment is poorly understood. One possibility is that they are all driven by impaired executive monitoring (Hilgard, 1977; Woody \& Sadler, 2008), a specific form of metacognition pertaining to intentions (Dienes \& Hutton, 2013; Dienes \& Perner, 2007), or a disruption of the coupling between monitoring and control (Egner et al., 2005; Jamieson \& Woody, 2007). As described above, recent research is consistent with a specific deficit in metacognition pertaining to intentions (Lush et al., 2016). Interpretation of the neurocognitive profile of highly suggestible individuals, however, is further complicated by research showing that some cognitive deficits in this population might be restricted to those who are also highly dissociative (Terhune et al., 2011c) (see §7.5). 
Electrophysiological and functional neuroimaging research has provided converging evidence that high hypnotic suggestibility is characterized by an atypical network connectivity profile. One study found that highly suggestible individuals exhibited reduced frontal-parietal phase synchrony in the upper alpha frequency band $(10.5-12 \mathrm{~Hz})$; importantly, this result, including its oscillatory specificity, was replicated (Terhune et al., 2011a). This is consistent with previous research indicating that highly suggestible individuals exhibit greater posterior upper alpha power (Williams \& Gruzelier, 2001). Other complementary research has suggested that highly suggestible individuals exhibit reduced anterior connectivity in the beta band but increased posterior connectivity in the theta band following an induction (Jamieson \& Burgess, 2014), which is in line with other resting state EEG findings (Isotani et al., 2001) and the observation of reduced frontal connectivity among highly suggestible individuals during a selective attention task following an induction (Egner et al., 2005). These and other results may be reconciled through a shift from an anterior to a posterior neurophysiological mode, as observed in patients with schizophrenia (Holt et al., 2011). Resting state studies on hypnosis have traditionally neglected individual differences in spontaneous perceptual states (Cardeña, 2005; Pekala \& Kumar, 2007) and thus despite somewhat convergent results, interpretation is still challenging. Preliminary research addressed this issue and observed that global functional connectivity following a minimal hypnotic induction was negatively associated with different dimensions of consciousness including anomalous perceptual states (Cardeña et al., 2013). Cumulatively, these studies seem to suggest that highly suggestible individuals exhibit reduced frontal connectivity, although further research is needed to clarify the oscillatory specificity of these effects. Multiple studies have suggested that variability in hypnotic suggestibility is associated with inter-individual differences in theta and gamma oscillations (Jensen, Adachi, \& Hakimian, 2015), although these results are not yet sufficiently reliable to qualify as a neural marker of suggestibility. Nevertheless, preliminary research indicates that theta oscillatory power may predict variability in hypnotic analgesia (Jensen, Hakimian, Sherlin, \& Fregni, 2008) and thus further research on the role of theta oscillations in hypnotic suggestibility is warranted.

The results of resting state fMRI and structural MRI provide complementary results that seem to further implicate atypical frontal functioning in high hypnotic suggestibility. Research has shown that highly 
suggestible individuals exhibit greater reductions in medial prefrontal or dorsal anterior cingulate cortex activation following an induction than low suggestible controls (Jiang et al., in press; McGeown et al., 2009) and that induction-specific reductions in activation of regions of the default mode network relate to spontaneous changes in cognitive and perceptual states (Deeley et al., 2012). A recent high powered study further showed that following an induction, highly suggestible individuals exhibit increased coupling between bilateral dorsolateral prefrontal and insular cortices (Jiang et al., in press). The study further found that reduced coupling between dorsolateral prefrontal cortex and posterior regions of the default mode network (e.g., posterior cingulate cortex) was associated with a greater subjective experience of being hypnotized. These results are potentially congruent with research on possession states, which have a number of cognitive and phenomenological parallels to hypnosis (Cardeña, Van Duijl, et al., 2009). Previous research found that individuals exhibit reduced activation of lateral prefrontal cortex during glossolalia singing, which is characterized by a pronounced reduction in one's sense of agency, relative to regular singing (Newberg, Wintering, Morgan, \& Waldman, 2006). Together, these results provide encouraging, but preliminary, evidence that high hypnotic suggestibility is characterized by atypical prefrontal functioning and connectivity and specifically implicates regions involved in self-related processing, monitoring, mind wandering, and cognitive control, thereby providing indirect evidence for the involvement of these functions in hypnosis.

Although promising, these seemingly convergent results need to be considered in the context of methodological limitations that are present in many of the foregoing studies. First, the studies vary considerably in the types of inductions used. Although different inductions are typically comparable in the extent to which they enhance suggestibility (see $\S 3$ ), subtle changes in the wording of suggestions can substantially impact neurophysiological responses (Barabasz et al., 1999). Accordingly, differential activation or connectivity patterns across studies may be artefactual of induction differences and thus any conclusions regarding inter-study commonalities should be taken as preliminary (Cardeña et al., 2013). A number of studies investigating the neurocognitive profile of highly suggestible individuals have also relied on an extreme-groups design involving the contrast of low and highly suggestible individuals (Lynn et al., 2007). Although not always, the use of this design is sometimes problematic because it potentially renders 
simple differences in a neurophysiological parameter equivocal: for example, a difference between these two groups may reflect an atypical neurophysiological profile in low, rather than highly, suggestible individuals.

For this reason, the inclusion of medium suggestible individuals as a control group or the inclusion of participants across the full spectrum of hypnotic suggestibility is important in establishing reliable neurophysiological markers of high hypnotic suggestibility (Cardeña et al., 2013; Huber et al., 2014).

Less well understood is how the brain implements responses to suggestion. There is preliminary, but encouraging, evidence for potentially overlapping neurophysiological mechanisms across studies examining the impact of hypnotic suggestions on brain states (Landry \& Raz, 2015). A range of studies have observed activation of subregions of frontal cortex and neighboring regions, such as anterior cingulate cortex during response to suggestion. In addition to modality-specific activation patterns, anterior cingulate cortex is reliably activated during hallucination suggestions and may underlie alterations in source monitoring necessary for the experience of such suggestions (Derbyshire et al., 2004; Landry \& Raz, 2015; McGeown et al., 2012; Szechtman et al., 1998). One study observed broad activations of lateral prefrontal and parietal cortices among highly suggestible individuals during response to a colour hallucination suggestion (McGeown et al., 2012). These regions comprise the frontal-parietal, executive attention, or multiple-demand network, a set of regions reliably activated across a range of operations (Woolgar, Jackson, \& Duncan, 2016) and thereby imply that the suggestion was implemented through normal cognitive control mechanisms. Similarly, research on posthypnotic amnesia observed activation of rostral prefrontal cortex which may underlie retrieval inhibition (Mendelsohn et al., 2008). Suggestions targeting motor phenomena typically involve broader activation differences including prefrontal, parietal and motor cortices and cerebellum (Blakemore et al., 2003; Cojan et al., 2009; Deeley et al., 2013), with multiple studies highlighting a specific involvement of precuneus (Cojan et al., 2009; Deeley et al., 2014).

These studies have yielded a number of convergent findings that corroborate participants' phenomenological responses and implicate regions and networks known to be involved in the respective phenomena. Nevertheless, extrapolating from this research to theories of hypnotic suggestion and/or using this research as a basis for identifying the neural substrates of response to suggestion remains a daunting 
challenge. Nearly all existing studies have investigated specific suggestions in isolation and thus there is little intra-study information regarding overlapping neurophysiological patterns associated with responses to different suggestions. As is the case with inductions, the wording of suggestions across studies is highly variable with suggestion structure differing considerably in length, the invocation of imagination, and other possible confounding factors. Research studies may not always be able to dissociate induction-specific from suggestion-specific neurophysiological patterns; this is especially critical given the results pointing to the alteration of anterior cingulate cortex following an induction (Jiang et al., in press) and in response to a variety of suggestions (Landry \& Raz, 2015). Many of these challenges can be overcome by precisely contrasting different suggestions to identify domain-general and domain-specific neurophysiological signatures and by standardizing inductions and suggestions across studies.

\section{Outstanding questions and future directions}

Despite clear advances in our knowledge of hypnosis, researchers and clinicians are still confronted with a multitude of pressing questions which we expect will guide and inform future research. A number of the challenges confronting this field stem from a reliance on outmoded research practices and conceptual orientations. Owing in part to taboos surrounding hypnosis, which are largely based in discredited myths (Raz, 2011), the field of experimental hypnosis research has also traditionally been relatively isolated from germane areas of psychology and neuroscience, such as research on cognitive control, meditation, or placebo analgesia. This isolation has undoubtedly further hindered methodological and theoretical progress and thus better integrating hypnosis within contemporary clinical and cognitive neuroscience has the potential to radically alter research and theory in the domain of hypnosis whilst also providing reciprocal benefits to other research areas.

Experimental hypnosis research critically depends on the robust measurement of hypnotic suggestibility (Woody \& Barnier, 2008): hypnotic suggestibility scales are essential for reliably identify highly suggestible individuals and relating hypnotic suggestibility to cognitive and neurophysiological variables. Despite their many strengths, the most widely used measures of hypnotic suggestibility are 
outdated (Bowers, 1993; Shor \& Orne, 1962; Weitzenhoffer \& Hilgard, 1962) and have a number of significant limitations pertaining to the mode of measurement and suggestion content (Bowers et al., 1988; Sadler \& Woody, 2004; Terhune, 2015; Terhune \& Cohen Kadosh, 2012; Woody \& Barnier, 2008). These measurement properties may reduce the precision of estimates of hypnotic suggestibility and will be especially problematic in studies where responsiveness to individual suggestions is measured (Bryant, Hung, Guastella, \& Mitchell, 2012; Dienes \& Hutton, 2013), and thus plausibly contribute to the difficulties in identifying reliable correlates of hypnotic suggestibility. Advancing the measurement of hypnotic suggestibility will be necessary to understand the neurocognitive profile of highly suggestible individuals and robustly index the cognitive and neurophysiological correlates of hypnotic suggestibility. Accordingly, we see the development of more advanced measures of hypnotic suggestibility to be one of the foremost goals in the coming years.

Hypnosis research can significantly benefit from research on germane phenomena. As described above, the principal phenomenological feature of response to a hypnotic suggestion is a reduction or disruption of the perception of authorship over one's actions and thoughts (Bowers, 1981; Polito et al., 2014). Despite the prominence of this experiential concomitant of hypnotic responding, relatively little hypnosis research (Haggard et al., 2004; Lush et al., 2016) has exploited knowledge gained from research on the sense of agency (Moore \& Haggard, 2010; Moore \& Obhi, 2012). In particular, harnessing methodologies developed to study normal and atypical sense of agency has the potential to usher in theoretical and methodological step changes in experimental hypnosis research. Moreover, highly suggestible individuals provide a potentially valuable population for studying distortions in the sense of agency in the general population (Polito et al., 2015) and thus we anticipate that research using these individuals to study broader questions pertaining to the sense of agency will become more commonplace.

Research will further benefit from a systematic assessment of the relations between hypnosis and hypnotic suggestibility and other phenomena for which suggestion seems to play an integral role (Halligan \& Oakley, 2014). For example, we anticipate that a major aim in future research will be to clarify the extent to which hypnosis has overlapping and/or distinct mechanisms with similar phenomena such as psychogenic 
disorders, which may be triggered by heightened responsiveness to illness cues in an individual's environment and share overlapping phenomenology with hypnosis (Brown \& Reuber, 2016; Edwards, 2017; Vuilleumier, 2014), placebo (De Pascalis et al., 2002), and suggestibility in forensic contexts (Gabbert \& Hope, 2013; Gudjonsson, 2013). More broadly, despite earlier attempts to integrate diverse suggestion-based phenomena (Gheorghiu et al., 1989), efforts to ground hypnosis within a broader domain of suggestion and suggestibility have stagnated in recent years (Halligan \& Oakley, 2014). However, such an endeavor will be of considerable value as researchers and clinicians address more thoroughly how the brain uses contextual information to influence perception, cognition, and behaviour both in experimental and clinical contexts (Wager \& Atlas, 2015). Studying hypnosis and germane phenomena in conjunction is expected to provide reciprocal benefits to these different domains and has the potentially to radically advance knowledge regarding the phenomenon of suggestion.

\section{Acknowledgments}

DBT was supported by Bial Foundation bursary 344/14.

\section{References}

Adachi, T., Fujino, H., Nakae, A., Mashimo, T., \& Sasaki, J. (2014). A meta-analysis of hypnosis for chronic pain problems: A comparison between hypnosis, standard care, and other psychological interventions. International Journal of Clinical and Experimental Hypnosis, 62, 1-28.

Agard, E., Pernod, C., El Chehab, H., Russo, A., Haxaire, M., \& Dot, C. (2016). A role for hypnosis in cataract surgery: Report of 171 procedures. Journal Francais d Ophtalmologie, 39(3), 287-291. doi: 10.1016/j.jfo.2015.04.024

Allen, J. J., Iacono, W. G., Laravuso, J. J., \& Dunn, L. A. (1995). An event-related potential investigation of posthypnotic recognition amnesia. Journal of Abnormal Psychology, 104, 421-430.

Augustinova, M., \& Ferrand, L. (2012). Suggestion does not de-automatize word reading: Evidence from the semantically based Stroop task. Psychon Bull Rev, 19(3), 521-527. doi: 10.3758/s13423-012-0217-y 
Barabasz, A., Barabasz, M., Jensen, S., Calvin, S., Trevisan, M., \& Warner, D. (1999). Cortical event-related potentials show the structure of hypnotic suggestions is crucial. International Journal of Clinical and Experimental Hypnosis, 47, 5-22. doi: 10.1080/00207149908410019

Barber, T. X. (1969). Hypnosis: A scientific approach. New York, NY: Van Nostrand Reinhold.

Barber, T. X. (1984). Changing "unchangeable" bodily processes by (hypnotic) suggestions. In A. A. Sheikh (Ed.), Imagination and healing (pp. 69-127). Farmingdale, NY: Baywood.

Barber, T. X. (1985). Hypnosuggestive procedures as catalysts for psychotherapies. In S. J. Lynn \& J. P. Garske (Eds.), Contemporary psychotherapies: Models and methods (pp. 333-376). Columbus, OH: Charles E. Merrill.

Barber, T. X. (1999). A comprehensive three-dimensional theory of hypnosis. In I. Kirsch, A. Capafons, E. Cardeña-Buelna \& S. Amigo (Eds.), Clinical hypnosis and self-regulation: Cognitive-behavioral perspectives (pp. 21-48). Washington, DC: American Psychological Association.

Barnier, A. J., Cox, R. E., \& McConkey, K. M. (2014). The province of "highs": The high hypnotizable person in the science of hypnosis and in psychological science. Psychology of Consciousness: Theory, Research, and Practice, 1(2), 168-183.

Barnier, A. J., Dienes, Z., \& Mitchell, C. J. (2008). How hypnosis happens: New cognitive theories of hypnotic responding. In M. Nash \& A. J. Barnier (Eds.), The Oxford handbook of hypnosis: Theory, research, and practice (pp. 141-178). Oxford, UK: Oxford University Press.

Barnier, A. J., \& McConkey, K. M. (1992). Reports of real and false memories: The relevance of hypnosis, hypnotizability, and context of memory test. J Abnorm Psychol, 101(3), 521-527.

Barnier, A. J., \& McConkey, K. M. (1999). Hypnotic and posthypnotic suggestion: Finding meaning in the message of the hypnotist. Int J Clin Exp Hypn, 47(3), 192-208. doi: 10.1080/00207149908410032

Bell, V., Oakley, D. A., Halligan, P. W., \& Deeley, Q. (2011). Dissociation in hysteria and hypnosis: Evidence from cognitive neuroscience. Journal of Neurology, Neurosurgery, and Psychiatry, 82(3), 332-339. doi: 10.1136/jnnp.2009.199158 
Benedetti, F. (2013). Placebo and the new physiology of the doctor-patient relationship. Physiological Reviews, 93(3), 1207-1246. doi: 10.1152/physrev.00043.2012

Benham, G., Woody, E. Z., Wilson, K. S., \& Nash, M. R. (2006). Expect the unexpected: Ability, attitude, and responsiveness to hypnosis. Journal of Personality and Social Psychology, 91(2), 342-350. doi: $10.1037 / 0022-3514.91 .2 .342$

Bentler, P. M., \& Hilgard, E. R. (1963). A comparison of group and individual induction of hypnosis with self-scoring and observer-scoring. International Journal of Clinical and Experimental Hypnosis, 11, $49-54$.

Bhavsar, V., Ventriglio, A., \& Bhugra, D. (2016). Dissociative trance and spirit possession: Challenges for cultures in transition. Psychiatry and Clinical Neurosciences, 70(12), 551-559. doi:

\section{$10.1111 / \mathrm{pcn} .12425$}

Birnie, K. A., Noel, M., Parker, J. A., Chambers, C. T., Uman, L. S., Kisely, S. R., \& McGrath, P. J. (2014). Systematic review and meta-analysis of distraction and hypnosis for needle-related pain and distress in children and adolescents. Journal of Pediatric Psychology, 39, 783-808.

Blakemore, S. J., Frith, C. D., \& Wolpert, D. M. (1999). Spatio-temporal prediction modulates the perception of self-produced stimuli. Journal of Cognitive Neuroscience, 11(5), 551-559.

Blakemore, S. J., Oakley, D. A., \& Frith, C. D. (2003). Delusions of alien control in the normal brain. Neuropsychologia, 41(8), 1058-1067.

Blakemore, S. J., Wolpert, D. M., \& Frith, C. D. (1998). Central cancellation of self-produced tickle sensation. Nature Neuroscience, 1(7), 635-640. doi: 10.1038/2870

Blanke, O., Ortigue, S., Landis, T., \& Seeck, M. (2002). Stimulating illusory own-body perceptions. Nature, 419(6904), 269-270. doi: 10.1038/419269a

Bowers, K. S. (1981). Do the Stanford Scales tap the "classic suggestion effect"? International Journal of Clinical and Experimental Hypnosis, 29(1), 42-53. doi: 10.1080/00207148108409142

Bowers, K. S. (1993). The Waterloo-Stanford Group C (WSGC) scale of hypnotic susceptibility: normative and comparative data. Int J Clin Exp Hypn, 41(1), 35-46. 
Bowers, P., Laurence, J. R., \& Hart, D. (1988). The experience of hypnotic suggestions. International Journal of Clinical and Experimental Hypnosis, 36(4), 336-349. doi: 10.1080/00207148808410523

Braffman, W., \& Kirsch, I. (1999). Imaginative suggestibility and hypnotizability: An empirical analysis. Journal of Personality and Social Psychology, 77(3), 578-587.

Braffman, W., \& Kirsch, I. (2001). Reaction time as a predictor of imaginative suggestibility and hypnotizability. Contemporary hypnosis, 18(3), 107-119.

Brown, D. P., \& Fromm, E. (1986). Hypnotherapy and hypnoanalysis. Hillsdale, NJ: Lawrence Erlbaum.

Brown, R. J., Antonova, E., Langley, A., \& Oakley, D. A. (2001). The effects of absorption and reduced critical though on suggestibility in an hypnotic context. Contemporary hypnosis, 18, 62-72.

Brown, R. J., \& Oakley, D. A. (2004). An integrative cognitive theory of hypnosis and high hypnotizability. In M. Heap, R. J. Brown \& D. A. Oakley (Eds.), The highly hypnotizable person: Theoretical, experimental and clinical issues (pp. 152-186). New York, NY: Brunner-Routledge.

Brown, R. J., \& Reuber, M. (2016). Psychological and psychiatric aspects of psychogenic non-epileptic seizures (PNES): A systematic review. Clinical Psychology Review, 45, 157-182. doi: 10.1016/j.cpr.2016.01.003

Bryant, R. A., Barnier, A. J., Mallard, D., \& Tibbits, R. (1999). Posthypnotic amnesia for material learned before hypnosis. Int J Clin Exp Hypn, 47(1), 46-64.

Bryant, R. A., Hung, L., Guastella, A. J., \& Mitchell, P. B. (2012). Oxytocin as a moderator of hypnotizability. Psychoneuroendocrinology, 37(1), 162-166. doi: 10.1016/j.psyneuen.2011.05.010

Buckner, R. L., Andrews - Hanna, J. R., \& Schacter, D. L. (2008). The brain's default network. Annals of the New York Academy of Sciences, 1124(1), 1-38.

Burgess, C. A., Kirsch, I., Shane, H., Niederauer, K. L., Graham, S. M., \& Bacon, A. (1998). Facilitated communication as an ideomotor response. Psychological Science, 9(1), 71-74. doi: Doi $10.1111 / 1467-9280.00013$

Cardeña, E. (2005). The phenomenology of deep hypnosis: Quiescent and physically active. International Journal of Clinical and Experimental Hypnosis, 53(1), 37-59. doi: 10.1080/00207140490914234 
Cardeña, E., Jonsson, P., Terhune, D. B., \& Marcusson-Clavertz, D. (2013). The neurophenomenology of neutral hypnosis. Cortex, 49(2), 375-385. doi: 10.1016/j.cortex.2012.04.001

Cardeña, E., \& Terhune, D. B. (2014). Hypnotizability, personality traits and the propensity to experience alterations of consciousness. Psychology of Consciousness: Theory, Research, and Practice, 1, 292307.

Cardeña, E., Terhune, D. B., Loof, A., \& Buratti, S. (2009). Hypnotic experience is related to emotional contagion. International Journal of Clinical and Experimental Hypnosis, 57(1), 33-46.

Cardeña, E., Van Duijl, M., Weiner, L., \& Terhune, D. B. (2009). Possession/trance phenomena. In P. F. Dell \& J. A. O'Neil (Eds.), Dissociation and the dissociative disorders: DSM-V and beyond (pp. 171181). New York, NY: Routledge.

Carlson, E. B., \& Putnam, F. W. (1989). Integrating research on dissociation and hypnotizability: Are there two pathways to hypnotizability? Dissociation, 2, 32-38.

Christoff, K., Gordon, A. M., Smallwood, J., Smith, R., \& Schooler, J. W. (2009). Experience sampling during fMRI reveals default network and executive system contributions to mind wandering. Proceedings of the National Academy of Sciences, 106(21), 8719-8724.

Cohen Kadosh, R., Henik, A., Catena, A., Walsh, V., \& Fuentes, L. J. (2009). Induced cross-modal synaesthetic experience without abnormal neuronal connections. Psychol Sci, 20(2), 258-265. doi: 10.1111/j.1467-9280.2009.02286.x

Cojan, Y., Piguet, C., \& Vuilleumier, P. (2015). What makes your brain suggestible? Hypnotizability is associated with differential brain activity during attention outside hypnosis. Neuroimage, 117, 367374. doi: 10.1016/j.neuroimage.2015.05.076

Cojan, Y., Waber, L., Schwartz, S., Rossier, L., Forster, A., \& Vuilleumier, P. (2009). The brain under selfcontrol: Modulation of inhibitory and monitoring cortical networks during hypnotic paralysis. Neuron, 62(6), 862-875. doi: 10.1016/j.neuron.2009.05.021

Colloca, L., \& Benedetti, F. (2009). Placebo analgesia induced by social observational learning. Pain, 144(12), 28-34. doi: 10.1016/j.pain.2009.01.033 
Comey, G., \& Kirsch, I. (1999). Intentional and spontaneous imagery in hypnosis: The phenomenology of hypnotic responding. International Journal of Clinical and Experimental Hypnosis, 47(1), 65-85. doi: $10.1080 / 00207149908410023$

Connors, M. H. (2015). Hypnosis and belief: A review of hypnotic delusions. Conscious Cogn, 36, 27-43. doi: 10.1016/j.concog.2015.05.015

Connors, M. H., Barnier, A. J., Coltheart, M., Cox, R. E., \& Langdon, R. (2012). Mirrored-self misidentification in the hypnosis laboratory: Recreating the delusion from its component factors. Cogn Neuropsychiatry, 17(2), 151-176. doi: 10.1080/13546805.2011.582287

Cook, S. W., \& Harris, R. E. (1937). The verbal conditioning of the galvanic skin reflex. Journal of Experimental Psychology, 21(2), 202-210.

Cox, R. E., \& Bryant, R. A. (2008). Advances in hypnosis research: Methods, designs and contributions of intrinsic and instrumental hypnosis. In M. Nash \& A. J. Barnier (Eds.), The Oxford handbook of hypnosis: Theory, research, and practice (pp. 311-336). Oxford, UK: Oxford University Press.

Crawford, H. J., Brown, A. M., \& Moon, C. E. (1993). Sustained attentional and disattentional abilities: differences between low and highly hypnotizable persons. J Abnorm Psychol, 102(4), 534-543.

de Guzman, M., Bird, G., Banissy, M. J., \& Catmur, C. (2016). Self-other control processes in social cognition: From imitation to empathy. Philosophical Transactions of the Royal Society of London. Series B: Biological Sciences, 371(1686), 20150079. doi: 10.1098/rstb.2015.0079

De Pascalis, V., Chiaradia, C., \& Carotenuto, E. (2002). The contribution of suggestibility and expectation to placebo analgesia phenomenon in an experimental setting. Pain, 96, 393-402. doi: 10.1016/S03043959(01)00485-7

Deeley, Q., Oakley, D. A., Toone, B., Bell, V., Walsh, E., Marquand, A. F., . . Halligan, P. W. (2013). The functional anatomy of suggested limb paralysis. Cortex, 49(2), 411-422. doi: 10.1016/j.cortex.2012.09.016 
Deeley, Q., Oakley, D. A., Toone, B., Giampietro, V., Brammer, M. J., Williams, S. C., \& Halligan, P. W. (2012). Modulating the default mode network using hypnosis. International Journal of Clinical and Experimental Hypnosis, 60(2), 206-228. doi: 10.1080/00207144.2012.648070

Deeley, Q., Oakley, D. A., Walsh, E., Bell, V., Mehta, M. A., \& Halligan, P. W. (2014). Modelling psychiatric and cultural possession phenomena with suggestion and fMRI. Cortex, 53, 107-119. doi: 10.1016/j.cortex.2014.01.004

Demacheva, I., Aubert-Bonn, N., Lucero, S., Ladouceur, M., \& Raz, A. (2012). Le role des facteurs developpementaux dans la determination de la responsabilite morale chez les jeunes: Une etude pilote evaluant les opinions d'experts legaux et cliniques. Criminologie, 45, 187-218.

Derbyshire, S. W., Whalley, M. G., \& Oakley, D. A. (2009). Fibromyalgia pain and its modulation by hypnotic and non-hypnotic suggestion: An fMRI analysis. Eur J Pain, 13(5), 542-550.

Derbyshire, S. W., Whalley, M. G., Stenger, V. A., \& Oakley, D. A. (2004). Cerebral activation during hypnotically induced and imagined pain. Neuroimage, 23(1), 392-401.

Dery, C., Campbell, N. K., Lifshitz, M., \& Raz, A. (2014). Suggestion overrides automatic audiovisual integration. Conscious Cogn, 24, 33-37. doi: 10.1016/j.concog.2013.12.010

Dienes, Z., Brown, E., Hutton, S., Kirsch, I., Mazzoni, G., \& Wright, D. B. (2009). Hypnotic suggestibility, cognitive inhibition, and dissociation. Consciousness and Cognition.

Dienes, Z., \& Hutton, S. (2013). Understanding hypnosis metacognitively: rTMS applied to left DLPFC increases hypnotic suggestibility. Cortex, 49(2), 386-392. doi: 10.1016/j.cortex.2012.07.009

Dienes, Z., Lush, P., Semmens-Wheeler, R., \& Naish, P. (2016). Hypnosis as self-deception: Meditation as self-insight. In A. Raz \& M. Lifshitz (Eds.), Hypnosis and meditation: Toward an integrative science of conscious planes. Oxford, UK: Oxford University Press.

Dienes, Z., \& Perner, J. (2007). Executive control without conscious awareness: The cold control theory of hypnosis. In G. A. Jamieson (Ed.), Hypnosis and conscious states: The cognitive neuroscience perspective (pp. 293-314). Oxford, UK: Oxford University Press. 
Dixon, M., Brunet, A., \& Laurence, J. R. (1990). Hypnotizability and automaticity: toward a parallel distributed processing model of hypnotic responding. J Abnorm Psychol, 99(4), 336-343.

Dixon, M., \& Laurence, J. R. (1992). Hypnotic susceptibility and verbal automaticity: Automatic and strategic processing differences in the Stroop color-naming task. J Abnorm Psychol, 101(2), 344347.

Dolby, R. M., \& Sheehan, P. W. (1977). Cognitive processing and expectancy behavior in hypnosis. $J$ Abnorm Psychol, 86(4), 334-345.

Edwards, M. J. (2017). Neurobiologic theories of functional neurologic disorders. Handb Clin Neurol, 139, 131-137. doi: 10.1016/B978-0-12-801772-2.00012-6

Egner, T., Jamieson, G., \& Gruzelier, J. (2005). Hypnosis decouples cognitive control from conflict monitoring processes of the frontal lobe. Neuroimage, 27(4), 969-978.

Egner, T., \& Raz, A. (2007). Cognitive control processes and hypnosis. In G. A. Jamieson (Ed.), Hypnosis and conscious states: The cognitive neuroscience perspective (pp. 29-50). Oxford, UK: Oxford University Press.

Elkins, G. (2017). Handbook of medical and psychological hypnosis: Foundations, applications, and professional issues. New York, NY: Springer.

Erickson, M. H., Rossi, E. L., \& Rossi, S. I. (1976). Hypnotic realities: The induction of hypnosis and forms of indirect suggestions. New York, NY: Irvington.

Facco, E. (2016). Hypnosis and anesthesia: Back to the future. Minerva Anestesiologica.

Farvolden, P., \& Woody, E. Z. (2004). Hypnosis, memory, and frontal executive functioning. International Journal of Clinical and Experimental Hypnosis, 52, 3-26.

Faymonville, M. E., Fissette, J., Mambourg, P. H., Roediger, L., Joris, J., \& Lamy, M. (1995). Hypnosis as an adjunct therapy in conscious sedation for plastic surgery. Regional Anesthesia and Pain Medicine, 20(2), 145-151. 
Flammer, E., \& Alladin, A. (2007). The efficacy of hypnotherapy in the treatment of psychosomatic disorders: Meta-analytical evidence. International Journal of Clinical and Experimental Hypnosis, $55,251-274$.

Flammer, E., \& Bongartz, W. (2003). On the efficacy of hypnosis: A meta-analytic study. Contemporary Hypnosis, 51, 179-197.

Fleming, S. M., Ryu, J., Golfinos, J. G., \& Blackmon, K. E. (2014). Domain-specific impairment in metacognitive accuracy following anterior prefrontal lesions. Brain, 137(Pt 10), 2811-2822. doi: 10.1093/brain/awu221

Frankel, F. H., Apfel-Savitz, R., Nemiah, J. C., \& Sifneos, P. E. (1977). The relationship between hypnotizability and alexithymia. Psychotherapy and Psychosomatics, 28, 172-178.

Freeman, L. P., Cox, R. E., \& Barnier, A. J. (2013). Transmitting delusional beliefs in a hypnotic model of folie a deux. Conscious Cogn, 22(4), 1285-1297. doi: 10.1016/j.concog.2013.07.011

Gabbert, F., \& Hope, L. (2013). Suggestibility and memory conformity. In A. M. Ridley, F. Gabbert \& D. J. La Rooy (Eds.), Suggestibility in legal contexts: Psychological research and forensic implications (pp. 63-83). Chichester, UK: Wiley-Blackwell.

Galea, V., Woody, E. Z., Szechtman, H., \& Pierrynowski, M. R. (2010). Motion in response to the hypnotic suggestion of arm rigidity: A window on underlying mechanisms. International Journal of Clinical and Experimental Hypnosis, 58(3), 251-268. doi: 10.1080/00207141003760561

Gandhi, B., \& Oakley, D. A. (2005). Does 'hypnosis' by any other name smell as sweet? The efficacy of 'hypnotic' inductions depends on the label 'hypnosis'. Consciousness and Cognition, 14(2), 304-315.

Gauld, A. (1992). A history of hypnotism. Cambridge, UK: Camridge University Press.

Gazzaley, A., \& D’Esposito, M. (2007). Unifying prefrontal cortex function: Executive control, neural networks and top-down modulation. In J. Cummings \& B. Miller (Eds.), The human frontal lobes (2nd ed.) (pp. 187-206). New York, NY: Guilford Press.

Gfeller, J. D., Lynn, S. J., \& Pribble, W. E. (1987). Enhancing hypnotic susceptibility: Interpersonal and rapport factors. Journal of Personality and Social Psychology, 52, 586-595. 
Gheorghiu, V. A., Netter, P., Eysenck, M., \& Rosenthal, R. (1989). Suggestion and suggestibility: Theory and research. Berlin, Germany: Springer Verlag.

Gorassini, D. R. (2004). Enhancing hypnotizability The highly hypnotizable person: Theoretical, experimental and clinical issues (pp. 213-239). New York, NY: Routledge.

Green, J. P., \& Lynn, S. J. (2000). Hypnosis and suggestion-based approaches to smoking cessation: An examination of the evidence. International Journal of Clinical and Experimental Hypnosis, 48, 195224.

Gruzelier, J. H. (2006). Frontal functions, connectivity and neural efficiency underpinning hypnosis and hypnotic susceptibility. Contemporary hypnosis, 23, 15-32.

Gudjonsson, G. H. (2013). Interrogative suggestibility and compliance. In A. M. Ridley, F. Gabbert \& D. J. La Rooy (Eds.), Suggestibility in legal contexts: Psychological research and forensic implications (pp. 45-61). Chichester, UK: Wiley-Blackwell.

Haggard, P., Cartledge, P., Dafydd, M., \& Oakley, D. A. (2004). Anomalous control: When 'free-will' is not conscious. Conscious Cogn, 13(3), 646-654.

Halligan, P. W., \& Oakley, D. A. (2014). Hypnosis and beyond: Exploring the broader domain of suggestion. Psychology of Consciousness: Theory, Research, and Practice, 1, 105-122. doi: 10.1037/cns0000019

Hammond, D. C., Haskins-Bartsch, C., Grant, C. W., \& McGhee, M. (1988). Comparison of self-directed and tape-assisted self-hypnosis. American Journal of Clinical Hypnosis, 31, 129-137.

Heap, M., Brown, R. J., \& Oakley, D. A. (2004). The highly hypnotizable person: Theoretical, experimental and clinical issues. New York, NY: Brunner-Routledge.

Hilgard, E. R. (1974). Toward a neo-dissociation theory: Multiple cognitive controls in human functioning. Perspectives in Biology and Medicine, 17(3), 301-316.

Hilgard, E. R. (1977). The problem of divided consciousness: A neodissociation interpretation. Annals of the New York Academy of Sciences, 296, 48-59.

Hilgard, J. R. (1979). Personality and hypnosis: A study of imaginative involvement. Chicago, IL: University of Chicago Press. 
Holt, D. J., Cassidy, B. S., Andrews-Hanna, J. R., Lee, S. M., Coombs, G., Goff, D. C., . . Moran, J. M. (2011). An anterior-to-posterior shift in midline cortical activity in schizophrenia during selfreflection. Biological Psychiatry, 69(5), 415-423. doi: 10.1016/j.biopsych.2010.10.003

Huber, A., Lui, F., Duzzi, D., Pagnoni, G., \& Porro, C. A. (2014). Structural and functional cerebral correlates of hypnotic suggestibility. PloS one, 9(3), e93187. doi: 10.1371/journal.pone.0093187

Hull, C. L. (1933). Hypnosis and suggestibility: An experimental approach. New York, NY: D. AppletonCentury Co.

Iani, C., Ricci, F., Gherri, E., \& Rubichi, S. (2006). Hypnotic suggestion modulates cognitive conflict: The case of the flanker compatibility effect. Psychol Sci, 17(8), 721-727.

Isotani, T., Lehmann, D., Pascual-Marqui, R. D., Kochi, K., Wackermann, J., Saito, N., . . Sasada, K. (2001). EEG source localization and global dimensional complexity in high- and low- hypnotizable subjects: a pilot study. Neuropsychobiology, 44(4), 192-198.

Jamieson, G. A., \& Burgess, A. P. (2014). Hypnotic induction is followed by state-like changes in the organization of EEG functional connectivity in the theta and beta frequency bands in highhypnotically susceptible individuals. Front Hum Neurosci, 8, 528. doi: 10.3389/fnhum.2014.00528

Jamieson, G. A., \& Sheehan, P. W. (2004). An empirical test of Woody and Bowers's dissociated-control theory of hypnosis. International Journal of Clinical and Experimental Hypnosis, 52(3), 232-249.

Jamieson, G. A., \& Woody, E. (2007). Dissociated control as a paradigm for cognitive neuroscience research and theorising in hypnosis. In G. A. Jamieson (Ed.), Hypnosis and conscious states: The cognitive neuroscience perspective (pp. 111-129). Oxford, UK: Oxford University Press.

Jensen, M. P., Adachi, T., \& Hakimian, S. (2015). Brain oscillations, hypnosis, and hypnotizability. Am J Clin Hypn, 57(3), 230-253. doi: 10.1080/00029157.2015.985573

Jensen, M. P., Hakimian, S., Sherlin, L. H., \& Fregni, F. (2008). New insights into neuromodulatory approaches for the treatment of pain. J Pain, 9(3), 193-199. doi: 10.1016/j.jpain.2007.11.003

Jiang, H., White, M. P., Greicius, M. D., Waelde, L. C., \& Spiegel, D. (in press). Brain activity and functional connectivity associated with hypnosis. Cerebral Cortex. doi: 10.1093/cercor/bhw220 
Jo, H. G., Hinterberger, T., Wittmann, M., \& Schmidt, S. (2015). Do meditators have higher awareness of their intentions to act? Cortex, 65, 149-158. doi: 10.1016/j.cortex.2014.12.015

Jones, T. F., Craig, A. S., Hoy, D., Gunter, E. W., Ashley, D. L., Barr, D. B., . . Schaffner, W. (2000). Mass psychogenic illness attributed to toxic exposure at a high school. New England Journal of Medicine, 342(2), 96-100. doi: 10.1056/NEJM200001133420206

Kallio, S., \& Revonsuo, A. (2003). Hypnotic phenomena and altered states of consciousness: A multilevel framework of description and explanation. Contemporary hypnosis, 20, 111-164.

Khodaverdi-Khani, M., \& Laurence, J.-R. (2016). Working memory and hypnotizability. Psychology of Consciousness: Theory, Research, and Practice, 3, 80-92.

Kihlstrom, J. F. (1997). Hypnosis, memory and amnesia. Philosophical Transactions of the Royal Society of London. Series B: Biological Sciences, 352(1362), 1727-1732. doi: 10.1098/rstb.1997.0155

Kihlstrom, J. F. (2008). The domain of hypnosis, revisited. In M. R. Nash \& A. J. Barnier (Eds.), The Oxford handbook of hypnosis (pp. 21-52). Oxford, UK: Oxford University Press.

King, B. J., \& Council, J. R. (1998). Intentionality during hypnosis: An ironic process analysis. International Journal of Clinical and Experimental Hypnosis, 46(3), 295-313.

Kirsch, I. (1999a). Clinical hypnosis as a nondeceptive placebo. In I. Kirsch, A. C.-B. Capafons, E. \& S. Amigo (Eds.), Clinical hypnosis and self-regulation (pp. 211-225). Washington, DC: American Psychological Association.

Kirsch, I. (1999b). Hypnosis and placebos: Response expectancy as a mediator of suggestion effects. Anales de Psicologia, 15, 99-110.

Kirsch, I., Capafons, A., Cardeña-Buelna, E., \& Amigo, S. (1999). Clinical hypnosis and self-regulation: Cognitive-behavioral perspectives. Washington, DC: American Psychological Association.

Kirsch, I., Council, J. R., \& Wickless, C. (1990). Subjective scoring for the Harvard Group Scale of Hypnotic Susceptibility, Form A. International Journal of Clinical and Experimental Hypnosis, 38(2), $112-$ 124. 
Kirsch, I., \& Lynn, S. J. (1998). Social-cognitive alternatives to dissociation theories of hypnotic involuntariness. Review of General Psychology, 2(1), 66-80.

Kirsch, I., Milling, L. S., \& Burgess, C. (1998). Experiential scoring for the Waterloo-Stanford Group C scale. International Journal of Clinical and Experimental Hypnosis, 46(3), 269-279.

Kirsch, I., Montgomery, G., \& Sapirstein, G. (1995). Hypnosis as an adjunct to cognitive-behavioral psychotherapy: A meta-analysis. Journal of Consulting and Clinical Psychology, 63, 214.

Kosslyn, S. M., Thompson, W. L., Costantini-Ferrando, M. F., Alpert, N. M., \& Spiegel, D. (2000). Hypnotic visual illusion alters color processing in the brain. American Journal of Psychiatry, 157(8), 1279-1284. doi: 10.1176/appi.ajp.157.8.1279

Kotov, R. I., Bellman, S. B., \& Watson, D. B. (2004). Multidimensional Iowa Suggestibility Scale (MISS). Stony Brook University. Retrieved 05/09/16, from https://medicine.stonybrookmedicine.edu/system/files/MISSBriefManual.pdf

Kühn, S., Brass, M., \& Haggard, P. (2013). Feeling in control: Neural correlates of experience of agency. Cortex, 49(7), 1935-1942. doi: 10.1016/j.cortex.2012.09.002

Laidlaw, T. M., \& Willett, M. J. (2002). Self - hypnosis tapes for anxious cancer patients: An evaluation using Personalised Emotional Index (PEI) diary data. Contemporary Hypnosis, 19, 25-33.

Landry, M., \& Raz, A. (2015). Hypnosis and imaging of the living human brain. American Journal of Clinical Hypnosis, 57(3), 285-313. doi: 10.1080/00029157.2014.978496

Landry, M., \& Raz, A. (2017). Neurophysiology of hypnosis. In G. Elkins (Ed.), Handbook of medical and psychological hypnosis: Foundations, applications, and professional issues (pp. 19-25). New York, NY: Springer.

Langdon, R., \& Coltheart, M. (2000). The cognitive neuropsychology of delusions. Mind and Language, 15, $184-218$.

Laurence, J., \& Perry, C. (1988). Hypnosis, will, and memory: A psycho-legal history. New York, NY: Guilford Press. 
Laurence, J.-R., Beaulieu-Prévost, D., \& du Chéné, T. (2008). Measuring and understanding individual differences in hypnotizability. In M. Nash \& A. J. Barnier (Eds.), The Oxford handbook of hypnosis: Theory, research and practice (pp. 225-253). Oxford, UK: Oxford University Press.

Laurence, J. R., \& Perry, C. (1983). Hypnotically created memory among highly hypnotizable subjects. Science, 222(4623), 523-524.

Libet, B., Gleason, C. A., Wright, E. W., \& Pearl, D. K. (1983). Time of conscious intention to act in relation to onset of cerebral activity (readiness-potential). Brain, 106(3), 623-642.

Loftus, E. (1997). Creating false memories. Seattle, WA: University of Washington.

London, P. (1965). Developmental experiments in hypnosis. Journal of Projective Techniques and Personality Assessment, 29, 189-199. doi: 10.1080/0091651X.1965.10120197

Ludwig, V. U., Stelzel, C., Krutiak, H., Magrabi, A., Steimke, R., Paschke, L. M., \& Walter, H. (2013). The suggestible brain: Posthypnotic effects on value-based decision-making. Social Cognitive and Affective Neuroscience. doi: 10.1093/scan/nst110

Lund, K., Petersen, G. L., Erlandsen, M., De Pascalis, V., Vase, L., Jensen, T. S., \& Finnerup, N. B. (2015). The magnitude of placebo analgesia effects depends on how they are conceptualized. Journal of Psychosomatic Research, 79(6), 663-668. doi: 10.1016/j.jpsychores.2015.05.002

Lush, P., Naish, P., \& Dienes, Z. (2016). Metacognition of intentions in mindfulness and hypnosis. Neuroscience of Consciousness, 1-10.

Lynn, S. J., \& Cardeña, E. (2007). Hypnosis and the treatment of posttraumatic conditions: An evidencebased approach. International Journal of Clinical and Experimental Hypnosis, 55, 167-188.

Lynn, S. J., Kirsch, I., \& Hallquist, M. (2008). Social cognitive theories of hypnosis. In M. R. Nash \& A. Barnier (Eds.), The Oxford handbook of hypnosis: Theory, research and practice (pp. 111-140). Oxford, UK: Oxford University Press.

Lynn, S. J., Kirsch, I., Knox, J., Fassler, O., \& Lilienfeld, S. O. (2007). Hypnosis and neuroscience: Implications for the altered state debate. In G. A. Jamieson (Ed.), Hypnosis and conscious states: The cognitive neuroscience perspective (pp. 145-165). Oxford, UK: Oxford University Press. 
Lynn, S. J., Laurence, J.-R., \& Kirsch, I. (2015). Hypnosis, suggestion, and suggestibility: An integrative model. American Journal of Clinical Hypnosis, 57, 314-329.

Lynn, S. J., Malaktaris, A., Maxwell, R., Mellinger, D., \& van der Kloet, D. (2012). Do hypnosis and mindfulness practices inhabit the same domain? Research, clinical, and forensic implications. MindBehavior Self Regulation, 12, 12-26.

Lynn, S. J., Matthews, A., \& Barnes, S. (2009). Hypnosis and memory: From Bernheim to the present. In K. Markman, W. Klein \& J. Suhr (Eds.), Handbook of imagination and mental stimulation. New York, NY: Psychology Press.

Lynn, S. J., Meyer, E., \& Shindler, K. (2004). Clinical correlates of high hypnotizability. In A. M. Brown (Ed.), The highly hypnotizable person: Theoretical, experimental, and clinical issues (pp. 187-212). London, UK: Brunner-Routledge.

Lynn, S. J., Nash, M. R., Rhue, J. W., Frauman, D. C., \& Sweeney, C. A. (1984). Nonvolition, expectancies, and hypnotic rapport. Journal of Abnormal Psychology, 93, 295-303.

Lynn, S. J., Neufeld, V. R., \& Mare, C. (1993). Direct versus indirect suggestions: A conceptual and methodological review. International Journal of Clinical and Experimental Hypnosis, 41, 124-152.

Lynn, S. J., Rhue, J., \& Kirsch, I. (2010). Handbook of clinical hypnosis (2nd ed.). Washington, DC: American Psychological Association.

Lynn, S. J., Snodgrass, M., Rhue, J. W., Nash, M. R., \& Frauman, D. C. (1987). Attributions, involuntariness, and hypnotic rapport. American Journal of Clinical Hypnosis, 30, 36-43.

Lynn, S. J., Weekes, J. R., Neufeld, V., Zivney, O., Brentar, J., \& Weiss, F. (1991). Interpersonal climate and hypnotizability level: Effects on hypnotic performance, rapport, and archaic involvement. Journal of Personality and Social Psychology, 60, 759.

Mason, M. F., Norton, M. I., Van Horn, J. D., Wegner, D. M., Grafton, S. T., \& Macrae, C. N. (2007). Wandering minds: the default network and stimulus-independent thought. Science, 315(5810), 393395. 
Mazzoni, G., Venneri, A., McGeown, W. J., \& Kirsch, I. (2013). Neuroimaging resolution of the altered state hypothesis. Cortex, 49(2), 400-410. doi: 10.1016/j.cortex.2012.08.005

McConkey, K. M., \& Barnier, A. J. (2004). High hypnotizability: Unity and diversity in behavior and experience. In M. Heap, R. J. Brown \& D. A. Oakley (Eds.), The highly hypnotizable person: Theoretical, experimental and clinical issues (pp. 61-84). New York, NY: Routledge.

McGeown, W. J., Mazzoni, G., Venneri, A., \& Kirsch, I. (2009). Hypnotic induction decreases anterior default mode activity. Consciousness and Cognition, 18(4), 848-855. doi:

10.1016/j.concog.2009.09.001

McGeown, W. J., Venneri, A., Kirsch, I., Nocetti, L., Roberts, K., Foan, L., \& Mazzoni, G. (2012). Suggested visual hallucination without hypnosis enhances activity in visual areas of the brain. Conscious Cogn, 21(1), 100-116. doi: 10.1016/j.concog.2011.10.015

Mendelsohn, A., Chalamish, Y., Solomonovich, A., \& Dudai, Y. (2008). Mesmerizing memories: Brain substrates of episodic memory suppression in posthypnotic amnesia. Neuron, 57(1), 159-170. doi: 10.1016/j.neuron.2007.11.022

Mertens, G., Raes, A. K., \& De Houwer, J. (2016). Can prepared fear conditioning result from verbal instructions? Learning and Motivation, 53, 7-23. Learning and Motivation, 53, 7-23.

Miele, D. B., Wager, T. D., Mitchell, J. P., \& Metcalfe, J. (2011). Dissociating neural correlates of action monitoring and metacognition of agency. Journal of Cognitive Neuroscience, 23(11), 3620-3636. doi: 10.1162/jocn_a_00052

Miller, E. K., \& Cohen, J. D. (2001). An integrative theory of prefrontal cortex function. Annual Review of Neuroscience, 24, 167-202. doi: 10.1146/annurev.neuro.24.1.167

Miller, G. A., Galanter, E., \& Pribram, K. H. (1960). Plans and the structure of behavior. New York, NY: Henry Holt \& Co.

Mink, J. W. (2013). Conversion disorder and mass psychogenic illness in child neurology. Annals of the New York Academy of Sciences, 1304, 40-44. doi: 10.1111/nyas.12298 
Montgomery, G. H., David, D., Winkel, G., Silverstein, J. H., \& Bovbjerg, D. H. (2002). The effectiveness of adjunctive hypnosis with surgical patients: A meta-analysis. Anesthesia and Analgesia, 94, 16391645 .

Montgomery, G. H., DuHamel, K. N., \& Redd, W. H. (2000). A meta-analysis of hypnotically induced analgesia: How effective is hypnosis? Int J Clin Exp Hypn, 48(2), 138-153.

Moore, J. W. (2016). What Is the sense of agency and why does it matter? Frontiers in psychology, 7, 1272. doi: $10.3389 /$ fpsyg.2016.01272

Moore, J. W., \& Haggard, P. (2010). Intentional binding and higher order agency experience. Conscious Cogn, 19(1), 490-491. doi: 10.1016/j.concog.2009.11.007

Moore, J. W., \& Obhi, S. S. (2012). Intentional binding and the sense of agency: A review. Conscious Cogn, 21(1), 546-561. doi: 10.1016/j.concog.2011.12.002

Moore, J. W., Ruge, D., Wenke, D., Rothwell, J., \& Haggard, P. (2010). Disrupting the experience of control in the human brain: Pre-supplementary motor area contributes to the sense of agency. Proc Biol Sci, 277(1693), 2503-2509. doi: 10.1098/rspb.2010.0404

Morgan, A. H. (1973). The heritability of hypnotic susceptibility in twins. J Abnorm Psychol, 82(1), 55-61.

Morgan, A. H., Hilgard, E. R., \& Davert, E. C. (1970). The heritability of hypnotic susceptibility of twins: A preliminary report. Behavior Genetics, 1(3), 213-224.

Morgan, A. H., \& Hilgard, J. R. (1978-79). The Stanford Hypnotic Clinical Scale for children. Am J Clin Hypn, 21(2-3), 148-169. doi: 10.1080/00029157.1978.10403969

Morgan, A. H., Johnson, D. L., \& Hilgard, E. R. (1974). The stability of hypnotic susceptibility: A longitudinal study. Int J Clin Exp Hypn, 22(3), 249-257.

Nash, M. R. (1997). Why scientific hypnosis needs psychoanalysis (or something like it). International Journal of Clinical and Experimental Hypnosis, 45, 291-300.

Nash, M. R. (2005). The importance of being earnest when crafting definitions: Science and scientism are not the same thing. International Journal of Clinical and Experimental Hypnosis, 53(3), 265-280. doi: $10.1080 / 00207140590961934$ 
Nash, M. R., Lynn, S. J., \& Stanley, S. M. (1984). The direct hypnotic suggestion of altered mind/body perception. American Journal of Clinical Hypnosis, 27, 95-102.

Newberg, A. B., Wintering, N. A., Morgan, D., \& Waldman, M. R. (2006). The measurement of regional cerebral blood flow during glossolalia: A preliminary SPECT study. Psychiatry Research, 148(1), 67-71. doi: 10.1016/j.pscychresns.2006.07.001

Nitzan, U., Chalamish, Y., Krieger, I., Erez, H. B., Braw, Y., \& Lichtenberg, P. (2015). Suggestibility as a predictor of response to antidepressants: A preliminary prospective trial. Journal of Affective Disorders, 185, 8-11. doi: 10.1016/j.jad.2015.06.028

Oakley, D. A., \& Halligan, P. W. (2009). Hypnotic suggestion and cognitive neuroscience. Trends Cogn Sci, 13(6), 264-270.

Oakley, D. A., \& Halligan, P. W. (2013). Hypnotic suggestion: Opportunities for cognitive neuroscience. Nature Reviews Neuroscience, 14(8), 565-576. doi: 10.1038/nrn3538

Oakman, J. M., \& Woody, E. Z. (1996). A taxometric analysis of hypnotic susceptibility. Journal of Personality and Social Psychology, 71(5), 980-991. doi: Doi 10.1037/0022-3514.71.5.980

Patterson, D. R. (2010). Clinical hypnosis for pain control. Washington, DC: American Psychological Association.

Patterson, D. R., Hoffman, H. G., Palacios, A. G., \& Jensen, M. J. (2006). Analgesic effects of posthypnotic suggestions and virtual reality distraction on thermal pain. J Abnorm Psychol, 115(4), 834-841.

Patterson, D. R., \& Jensen, M. P. (2003). Hypnosis and clinical pain. Psychological Bulletin, 129(4), 495521.

Pekala, R. J., \& Kumar, V. K. (2007). An empirical-phenomenological approach to quantifying consciousness and states of consciousness: With particular reference to understanding the nature of hypnosis. In G. A. Jamieson (Ed.), Hypnosis and conscious states: The cognitive neuroscience perspective (pp. 167-194). Oxford, UK: Oxford University Press.

Piccione, C., Hilgard, E. R., \& Zimbardo, P. G. (1989). On the degree of stability of measured hypnotizability over a 25-year period. Journal of Personality and Social Psychology, 56(2), 289-295. 
Polito, V., Barnier, A. J., \& Woody, E. Z. (2013). Developing the Sense of Agency Rating Scale (SOARS): An empirical measure of agency disruption in hypnosis. Consciousness and Cognition, 22(3), 684696. doi: 10.1016/j.concog.2013.04.003

Polito, V., Barnier, A. J., Woody, E. Z., \& Connors, M. H. (2014). Measuring agency change across the domain of hypnosis. Psychology of Consciousness: Theory, Research, and Practice, 1(1), 3-19.

Polito, V., Langdon, R., \& Barnier, A. J. (2015). Sense of agency across contexts: Insights from schizophrenia and hypnosis. Psychology of Consciousness: Theory, Research, and Practice, 2(3), 301-314.

Priftis, K., Schiff, S., Tikhonoff, V., Giordano, N., Amodio, P., Umilta, C., \& Casiglia, E. (2011). Hypnosis meets neuropsychology: Simulating visuospatial neglect in healthy participants. Neuropsychologia, 49(12), 3346-3350. doi: 10.1016/j.neuropsychologia.2011.08.008

Raes, A. K., De Houwer, J., De Schryver, M., Brass, M., \& Kalisch, R. (2014). Do CS-US pairings actually matter? A within-subject comparison of instructed fear conditioning with and without actual CS-US pairings. PloS one, 9(1), e84888. doi: 10.1371/journal.pone.0084888

Raichle, M. E. (2015). The brain's default mode network. Annual review of neuroscience(0).

Rainville, P., Carrier, B., Hofbauer, R. K., Bushnell, M. C., \& Duncan, G. H. (1999). Dissociation of sensory and affective dimensions of pain using hypnotic modulation. Pain, 82(2), 159-171.

Rainville, P., Duncan, G. H., Price, D. D., Carrier, B., \& Bushnell, M. C. (1997). Pain affect encoded in human anterior cingulate but not somatosensory cortex. Science, 277(5328), 968-971.

Raz, A. (2011). Hypnosis: A twilight zone of the top-down variety: Few have never heard of hypnosis but most know little about the potential of this mind-body regulation technique for advancing science. Trends Cogn Sci, 15(12), 555-557. doi: 10.1016/j.tics.2011.10.002

Raz, A. (2012). Hypnosis as a lens to the development of attention. Conscious Cogn, 21(3), 1595-1598. doi: 10.1016/j.concog.2012.05.011

Raz, A., \& Buhle, J. (2006). Typologies of attentional networks. Nature reviews. Neuroscience, 7(5), 367379. doi: $10.1038 / \mathrm{nrn} 1903$ 
Raz, A., Fan, J., \& Posner, M. I. (2005). Hypnotic suggestion reduces conflict in the human brain. Proceedings of the National Academy of Sciences of the United States of America, 102(28), 99789983. doi: 10.1073/pnas.0503064102

Raz, A., Kirsch, I., Pollard, J., \& Nitkin-Kaner, Y. (2006). Suggestion reduces the stroop effect. Psychological Science, 17(2), 91-95.

Raz, A., \& Lifshitz, M. (2016). Hypnosis and meditation: Toward an integrative science of conscious planes. Oxford, UK: Oxford University Press.

Reyher, J. (1962). A paradigm for determining the clinical relevance of hypnotically induced psychopathology. Psychological Bullletin, 59, 344-352.

Rhue, J. (2004). Developmental determinants of high hypnotizability. In M. Heap, R. J. Brown \& D. A. Oakley (Eds.), The highly hypnotizable person: Theoretical, experimental and clinical issues (pp. 115-132). New York, NY: Brunner-Routledge.

Richardson, J., Smith, J. E., McCall, G., Richardson, A., Pilkington, K., \& Kirsch, I. (2007). Hypnosis for nausea and vomiting in cancer chemotherapy: A systematic review of the research evidence. European Journal of Cancer Care, 16, 402-412.

Röder, C. H., Michal, M., Overbeck, G., van de Ven, V. G., \& Linden, D. E. (2007). Pain response in depersonalization: A functional imaging study using hypnosis in healthy subjects. Psychotherapy and Psychosomatics, 76(2), 115-121.

Roelofs, K., Hoogduin, K. A., Keijsers, G. P., Naring, G. W., Moene, F. C., \& Sandijck, P. (2002). Hypnotic susceptibility in patients with conversion disorder. Journal of Abnormal Psychology, 111(2), 390395.

Rominger, C., Weiss, E. M., Nagl, S., Niederstatter, H., Parson, W., \& Papousek, I. (2014). Carriers of the COMT Met/Met allele have higher degrees of hypnotizability, provided that they have good attentional control: A case of gene-trait interaction. Int J Clin Exp Hypn, 62(4), 455-482. doi: $10.1080 / 00207144.2014 .931177$

Rosenthal, D. (2005). Consciousness and mind. Oxford, UK: Oxford University Press. 
Sadler, P., \& Woody, E. Z. (2004). Four decades of group hypnosis scales: What does item-response theory tell us about what we've been measuring? Int J Clin Exp Hypn, 52(2), 132-158.

Sapp, M. (2017). Obesity and weight loss. In G. Elkins (Ed.), Handbook of medical and psychological hypnosis: Foundations, applications, and professional issues (pp. 589-598). New York, NY: Springer Publishing Company.

Schaefert, R., Klose, P., Moser, G., \& Häuser, W. (2014). Efficacy, tolerability, and safety of hypnosis in adult irritable bowel syndrome: Systematic review and meta-analysis. Psychosomatic Medicine, 76, 389-398.

Schoenberger, N. E., Kirsch, I., Gearan, P., Montgomery, G., \& Pastyrnak, S. L. (1997). Hypnotic enhancement of a cognitive behavioral treatment for public speaking anxiety. Behavior Therapy, 28 , 127-140.

Sheehan, P. W. (1991). Hypnosis, context, and commitment. In S. J. Lynn \& J. W. Rhue (Eds.), Theories of hypnosis: Current models and perspectives (pp. 520-541). New York, NY: Guilford Press.

Sheiner, E. O., Lifshitz, M., \& Raz, A. (2016). Placebo response correlates with hypnotic suggestibility. Psychology of Consciousness: Theory, Research, and Practice, 3(2), 146-153.

Shih, M., Yang, Y. H., \& Koo, M. (2009). A meta-analysis of hypnosis in the treatment of depressive symptoms: A brief communication. International Journal of Clinical and Experimental Hypnosis, $57,431-432$.

Shor, R. E., \& Orne, E. C. (1962). Harvard Group Scale of Hypnotic Susceptibility, Form A. Palo Alto, CA: Consulting Psychologists Press.

Spanos, N. P., \& Gorassini, D. R. (1984). Structure of hypnotic test suggestions and attributions of responding involuntarily. Journal of Personality and Social Psychology, 46(3), 688-696. doi: Doi $10.1037 / / 0022-3514.46 .3 .688$

Summerfield, C., \& de Lange, F. P. (2014). Expectation in perceptual decision making: Neural and computational mechanisms. Nature Reviews Neuroscience, 15, 745-756. doi: 10.1038/nrn3838 
Swider, K., \& Babel, P. (2013). The effect of the sex of a model on nocebo hyperalgesia induced by social observational learning. Pain, 154(8), 1312-1317. doi: 10.1016/j.pain.2013.04.001

Szechtman, H., \& Woody, E. (2004). Obsessive-compulsive disorder as a disturbance of security motivation. Psychological Review, 111(1), 111-127. doi: 10.1037/0033-295X.111.1.111

Szechtman, H., Woody, E., Bowers, K. S., \& Nahmias, C. (1998). Where the imaginal appears real: A positron emission tomography study of auditory hallucinations. Proceedings of the National Academy of Sciences of the United States of America, 95(4), 1956-1960.

Tart, C. T., \& Hilgard, E. R. (1966). Responsiveness to suggestions under "hypnosis" and "wakingimagination" conditions: A methodological observation. International Journal of Clinical and Experimental Hypnosis, 14(3), 247-256. doi: 10.1080/00207146608412967

Tasso, A. F., \& Perez, N. (2008). Parsing everyday suggestibility: What does it tell us about hypnosis? In M. R. Nash \& A. Barnier (Eds.), The Oxford handbook of hypnosis: Theory, research, and practice (pp. 283-309). Oxford, UK: Oxford University Press.

Tefikow, S., Barth, J., Maichrowitz, S., Beelmann, A., Strauss, B., \& Rosendahl, J. (2013). Efficacy of hypnosis in adults undergoing surgery or medical procedures: A meta-analysis of randomized controlled trials. Clinical Psychology Review, 33, 623-636.

Tellegen, A. (1981). Practicing the two disciplines for relaxation and enlightenment: Comment on "Role of the feedback signal in electromyograph biofeedback: The relevance of attention" by Qualls and Sheehan. Journal of Experimental Psychology: General, 110, 217-226.

Terhune, D. B. (2015). Discrete response patterns in the upper range of hypnotic suggestibility: A latent profile analysis. Consciousness and Cognition, 33, 334-341. doi: 10.1016/j.concog.2015.01.018

Terhune, D. B., \& Brugger, P. (2011). Doing better by getting worse: Posthypnotic amnesia improves random number generation. PloS one, 6(12), e29206. doi: 10.1371/journal.pone.0029206

Terhune, D. B., \& Cardeña, E. (2015). Dissociative subtypes in posttraumatic stress disorders and hypnosis: Neurocognitive parallels and clinical implications. Current Directions in Psychological Science, 24, 452-457. doi: 10.1177/0963721415604611 
Terhune, D. B., \& Cardeña, E. (2016). Nuances and uncertainties regarding hypnotic inductions: Toward a theoretically informed praxis. Am J Clin Hypn, 59(2), 155-174. doi:

$10.1080 / 00029157.2016 .1201454$

Terhune, D. B., Cardena, E., \& Lindgren, M. (2010). Disruption of synaesthesia by posthypnotic suggestion: An ERP study. Neuropsychologia, 48(11), 3360-3364. doi: 10.1016/j.neuropsychologia.2010.07.004

Terhune, D. B., Cardeña, E., \& Lindgren, M. (2011a). Differential frontal-parietal phase synchrony during hypnosis as a function of hypnotic suggestibility. Psychophysiology, 48(10), 1444-1447. doi:

10.1111/j.1469-8986.2011.01211.x

Terhune, D. B., Cardeña, E., \& Lindgren, M. (2011b). Dissociated control as a signature of typological variability in high hypnotic suggestibility. Consciousness and Cognition, 20(3), 727-736. doi: 10.1016/j.concog.2010.11.005

Terhune, D. B., Cardeña, E., \& Lindgren, M. (2011c). Dissociative tendencies and individual differences in high hypnotic suggestibility. Cogn Neuropsychiatry, 16(2), 113-135. doi:

$10.1080 / 13546805.2010 .503048$

Terhune, D. B., \& Cohen Kadosh, R. (2012). The emerging neuroscience of hypnosis. Cortex, 48, 382-386.

Tomes, J. L., \& Katz, A. N. (1997). Habitual susceptibility to misinformation and individual differences in eyewitness memory. Applied Cognitive Psychology, 11, 233-251.

Van Der Does, A. J. W., Van Dyck, R., Spinhoven, P., \& Kloosman, A. (1989). The effectiveness of standardized versus individualized hypnotic suggestions: A brief communication. International Journal of Clinical and Experimental Hypnosis, 37, 1-5.

Varga, K., \& Kekecs, Z. (2015). Feature-based coding system: A new way of characterizing hypnosis styles. International Journal of Clinical and Experimental Hypnosis, 63, 215-235.

Varga, S., \& Varga, K. (2009). Visual imaginative synchrony. Contemporary hypnosis, 26, 146-158.

Vuilleumier, P. (2014). Brain circuits implicated in psychogenic paralysis in conversion disorders and hypnosis. Neurophysiologie Clinique-Clinical Neurophysiology, 44(4), 323-337. doi: 10.1016/j.neucli.2014.01.003 
Wager, T. D., \& Atlas, L. Y. (2015). The neuroscience of placebo effects: Connecting context, learning and health. Nature reviews. Neuroscience, 16(7), 403-418. doi: 10.1038/nrn3976

Walsh, E., Oakley, D. A., Halligan, P. W., Mehta, M. A., \& Deeley, Q. (2015). The functional anatomy and connectivity of thought insertion and alien control of movement. Cortex, 64, 380-393. doi: 10.1016/j.cortex.2014.09.012

Wegner, D. (2002). The illusion of conscious will. Cambridge, MA: MIT Press.

Weitzenhoffer, A. M. (1974). When is an "instruction" an "instruction"? Int J Clin Exp Hypn, 22(3), 258269. doi: $10.1080 / 00207147408413005$

Weitzenhoffer, A. M. (1980). Hypnotic susceptibility revisited. American Journal of Clinical Hypnosis, $22(3), 130-146$.

Weitzenhoffer, A. M., \& Hilgard, E. R. (1962). Stanford Hypnotic Susceptibility Scale: Form C. Palo Alto, CA: Consulting Psychologists Press.

Weitzenhoffer, A. M., \& Hilgard, E. R. (1967). Revised Stanford Profile Scales of Hypnotic Susceptibility: Forms I and II. Palo Alto, CA: Consulting Psychologists Press.

Whalley, M. G., \& Brooks, G. B. (2009). Enhancement of suggestibility and imaginative ability with nitrous oxide. Psychopharmacology, 203(4), 745-752.

Wheatley, T., \& Haidt, J. (2005). Hypnotic disgust makes moral judgments more severe. Psychol Sci, 16(10), 780-784. doi: 10.1111/j.1467-9280.2005.01614.x

Wickramasekera, I. E. (2015). Mysteries of hypnosis and the self are revealed by the psychology and neuroscience of empathy. American Journal of Clinical Hypnosis, 57, 330-348.

Wickramasekera, I. E., 2nd, \& Szlyk, J. P. (2003). Could empathy be a predictor of hypnotic ability? Int J Clin Exp Hypn, 51(4), 390-399.

Williams, J. D., \& Gruzelier, J. H. (2001). Differentiation of hypnosis and relaxation by analysis of narrow band theta and alpha frequencies. Int J Clin Exp Hypn, 49(3), 185-206.

Winkel, J. D., Younger, J. W., Tomcik, N., Borckardt, J. J., \& Nash, M. R. (2006). Anatomy of a hypnotic response: Self-report estimates, actual behavior, and physiological response to the hypnotic 
suggestion of arm rigidity. International Journal of Clinical and Experimental Hypnosis, 54, 186205.

Woody, E., \& Szechtman, H. (2007a). To see feelingly: Emotion, motivation and hypnosis. In G. A. Jamieson (Ed.), Hypnosis and conscious states: The cognitive neuroscience perspective (pp. 241255 ). Oxford, UK: Oxford University Press.

Woody, E. Z., \& Barnier, A. J. (2008). Hypnosis scales for the twenty-first century: What do we know and how should we use them? In M. Nash \& A. J. Barnier (Eds.), The Oxford handbook of hypnosis: Theory, research and practice (pp. 255-281). Oxford, UK: Oxford University Press.

Woody, E. Z., Barnier, A. J., \& McConkey, K. M. (2005). Multiple hypnotizabilities: Differentiating the building blocks of hypnotic response. Psychological Assessment, 17(2), 200-211.

Woody, E. Z., \& Bowers, K. S. (1994). A frontal assault on dissociated control. In S. J. Lynn \& J. W. Rhue (Eds.), Dissociation: Clinical and theoretical perspectives (pp. 52-79). New York, NY: Guilford.

Woody, E. Z., Drugovic, M., \& Oakman, J. M. (1997). A reexamination of the role of nonhypnotic suggestibility in hypnotic responding. Journal of Personality and Social Psychology, 72(2), 399-407.

Woody, E. Z., Lewis, V., Snider, L., Grant, H., Kamath, M., \& Szechtman, H. (2005). Induction of compulsive-like washing by blocking the feeling of knowing: an experimental test of the securitymotivation hypothesis of obsessive-compulsive disorder. Behav Brain Funct, 1, 11. doi: $10.1186 / 1744-9081-1-11$

Woody, E. Z., \& McConkey, K. M. (2003). What we don't know about the brain and hypnosis, but need to: A view from the Buckhorn Inn. Int J Clin Exp Hypn, 51(3), 309-338.

Woody, E. Z., \& Sadler, P. (2008). Dissociation theories of hypnosis. In M. Nash \& A. J. Barnier (Eds.), The Oxford handbook of hypnosis: Theory, research and practice (pp. 81-110). Oxford, UK: Oxford University Press.

Woody, E. Z., \& Szechtman, H. (2007b). To see feelingly: Emotion, motivation, and hypnosis. In G. A. Jamieson (Ed.), Hypnosis and conscious states: The cognitive neuroscience perspective (pp. 241256). Oxford, UK: Oxford University Press. 
Woody, E. Z., \& Szechtman, H. (2011). Using hypnosis to develop and test models of psychopathology. Journal of Mind-Body Regulation, 1, 4-16.

Woolgar, A., Jackson, J., \& Duncan, J. (2016). Coding of visual, auditory, rule, and response information in the brain: 10 years of multivoxel pattern analysis. Journal of Cognitive Neuroscience, 28(10), 14331454. doi: 10.1162/jocn_a_00981 